\title{
El género Stevia (Eupatorieae, Asteraceae) en el estado de Morelos, México
}

\section{The genus Stevia (Eupatorieae, Asteraceae) in the state of Morelos, Mexico}

\author{
Erika Villagómez-Flores' (D), Oscar Hinojosa-Espinosa1,2 [D, José Luis Villaseñor 1,3 (1)
}

1 Universidad Nacional Autónoma de México, Instituto de Biología, Apdo. postal 70-233, O4510 Delegación Coyoacán, Cd. Mx., México.

2 University of California, Davis, Department of Plant Sciences, One Shields Avenue, CA 95616, USA.

3 Autor para la correspondencia: vrios@ib.unam.mx

Recibido: 16 de noviembre de 2017. Revisado: 4 de diciembre de 2017. Aceptado: 12 de febrero de 2018 Prímero en línea: 8 de agosto de 2018. Publicado: 3 de octubre de 2018

Citar como:

Villágomez-Flores, E., O. Hinojosa-Espinosa y J. L. Villaseñor. 2018. El género Stevia (Eupatorieae, Asteraceae) en el estado de Morelos, México. Acta Botanica Mexicana 125: 7-36. DOI: 10.21829/ abml25.2018.1315

DOI:

10.21829/abml25.2018.1315

\section{Resumen:}

Antecedentes y Objetivos: El género Stevia (Eupatorieae) es el tercero más diverso de la familia Asteraceae en México, con 116 especies, de las cuales 107 son endémicas del país. Sus especies se caracterizan por presentar un involucro cilíndrico, uniseriado, formado por cinco brácteas que rodean a cinco flores y aquenios cilíndricos a fusiformes; por lo general con un vilano de escamas, escamas y aristas, o coroniforme. Si bien Stevia es un género relativamente fácil de reconocer, la identificación de sus especies suele ser bastante complicada debido a que muchas de ellas no están claramente delimitadas; además, varias hibridan o se reproducen de manera apomíctica. Por lo tanto, como una primera estrategia encaminada a mejorar el conocimiento de Stevia en México, se presenta una sinopsis taxonómica de este género en el estado de Morelos, el cual incluye una quinta parte de las especies mexicanas.

Métodos: Se estudiaron con detalle los ejemplares del Herbario Nacional de México (MEXU) y de algunos otros herbarios nacionales y extranjeros. Con el análisis de los ejemplares se realizaron las descripciones y la clave, y con las etiquetas de recolecta se sintetizaron los datos ecogeográficos de las especies. Las localidades de recolecta se georreferenciaron para elaborar los mapas de distribución.

Resultados clave: Se presenta una sinopsis del género para Morelos, que incluye una clave para la identificación de las especies, descripciones de cada una de ellas y mapas ilustrando su distribución geográfica en el estado.

Conclusiones: En el estado de Morelos se registran 25 especies del género, 17 de ellas endémicas de México. Las especies crecen preferentemente en los bosques templados del estado, sobre todo en los bosques de pino-encino y de encino, con unas pocas de ellas tolerando los ambientes tropicales de las partes bajas.

Palabras clave: Compositae, distribución geográfica, endemismo, florística, taxonomía.

\section{ABSTRACT:}

Background and Aims: The genus Stevia (Eupatorieae) is the third most diverse of the family Asteraceae in Mexico, with 116 species, of which 107 are endemic to the country. Its species are characterized by a cylindrical, uniseriate involucre, consisting of five bracts surrounding five flowers and cylindrical to fusiform achenes, usually with a pappus of scales, scales and awns or coroniform. Even though it is relatively simple to recognize the genus Stevia, the identification of its species is often quite complicated, as many species are not clearly delimitated, and in addition many hybridize or form apomictic populations. Hence, as a first strategy to improve the knowledge of the genus Stevia in Mexico, a taxonomic synopsis of the genus was carried out in the state of Morelos, which includes one fifth of the Mexican species.

Methods: The specimens of the National Herbarium of Mexico (MEXU), as well as specimens from other national and foreign herbaria were studied in detail. Based on examination of the specimens the descriptions and key were prepared, and from the collection labels the ecogeographical data of the species were synthesized. The locations were georeferenced to elaborate the distribution maps.

Key results: A synopsis of the genus for Morelos is presented, which includes a key for the identification of the species, descriptions of each of them and maps illustrating their geographical distribution in the state.

Conclusions: In the state of Morelos, there are 25 species of the genus, 17 of them endemic to Mexico. The species grow preferentially in the temperate forests of the state, especially in the pine-oak and oak forests, with a few of them tolerating the tropical lowland environments.

Key words: Compositae, endemism, floristics, geographical distribution, taxonomy. 


\section{INTRODUCCIÓN}

Stevia Cav. es un género característico del continente americano, miembro de la tribu Eupatorieae, familia Asteraceae (Robinson et al., 2009). El género actualmente se ha vuelto muy popular debido a que a partir de la especie sudamericana S. rebaudiana (Bertoni) Bertoni, se extraen edulcorantes bajos en calorías, los cuales se han estado usando a nivel mundial como substitutos del azúcar (Oviedo-Pereira et al., 2015). Stevia contiene unas 250 especies y se distribuye desde el sur de Estados Unidos de América hasta Argentina y Brasil (King y Robinson, 1987; Hind y Robinson, 2007; Turner, 2015). En México se registran 116 especies de Stevia, de las cuales 107 son endémicas del territorio nacional (Villaseñor, 2016). El género es uno de los 18 más diversos de las plantas vasculares mexicanas y el tercero más diverso de las Asteraceae de México, sólo por debajo de Ageratina Spach y Verbesina L. (165 especies cada uno) (Villaseñor, 2016).

Las especies de Stevia muestran una gran variación en sus formas de crecimiento, encontrándose tanto hierbas anuales como perennes, sufrútices o arbustos y pueden presentar hojas opuestas o alternas. Poseen consistentemente cabezuelas homógamas, discoides, formadas siempre por cinco brácteas involucrales conteniendo cinco flores del disco, corolas infundibuliformes, color blanco, rosadas o moradas. Las cabezuelas por lo general están dispuestas en grupos paniculiformes, amplios y laxos o corimbiformes, compactos y densos. Su vilano está constituido por escamas y aristas o sólo escamas, ya sea libres o unidas formando una corona; solamente $S$. hintonii (Grashoff) B.L. Turner carece de vilano (Grashoff, 1972). La principal característica diagnóstica de Stevia es que la cabezuela está constituida por cinco brácteas involucrales con cinco flores del disco (Grashoff, 1972; Bremer et al., 1994; Hind y Robinson, 2007); por esta razón, es difícil confundirlo con otras Eupatorieae. Quizá el único género con el cual puede confundirse es Carphochaete A. Gray (en especial C. pringlei (S. Watson) Grashoff ex B.L. Turner), ya que el hábito y la forma de sus capítulos y corolas son muy similares; sin embargo, Carphochaete tiene más de cinco flores por cabezuela y las aristas del vilano son también más de cinco (Turner, 1997).

Aunque las especies de Stevia son fáciles de reconocer a nivel genérico, la identificación a nivel de especie por lo general resulta complicada. Esto se debe en parte a que muchas especies no están claramente delimitadas; además, varias de ellas hibridan o contienen poblaciones apomícticas (Grashoff, 1972). Estos fenómenos dan como resultado la aparición de individuos con características intermedias entre dos o más especies.

Otro aspecto que causa en ocasiones confusión es que en algunas especies de Stevia se observa una variación en el vilano de los aquenios de una misma cabezuela (King y Robinson, 1987). En las especies con aquenios heteromorfos, tres o cuatro de ellos (conocidos como adelfocarpos) presentan un vilano de tres a cinco aristas, alternadas con escamas, mientras que el aquenio o aquenios restantes (conocidos como idiocarpos), poseen un vilano diferente, por lo general coroniforme (Figs. 1A, B). Por otro lado, en las especies con aquenios isomorfos (Fig. 1C), los cinco aquenios de una misma cabezuela poseen el mismo tipo de vilano, por lo general coroniforme o a veces de aristas y escamas.

Con respecto al conocimiento florístico y taxonómico de Stevia en el estado de Morelos, hasta el momento sólo se cuenta con el inventario florístico de Bonilla-Barbosa y Villaseñor (2003), quienes reportan 31 especies, así como la actualización realizada por Villaseñor (2016). Para el estado se reportan 3491 especies de plantas vasculares; de ellas, son 505 de Asteraceae y 25 de Stevia (Villaseñor, 2016). Como una estrategia encaminada a una mejor noción de Stevia en México, se planteó esta primera etapa de sintetizar el conocimiento acumulado para el género en el estado de Morelos, el cual incluye una quinta parte de la riqueza total conocida de Stevia en el país. Se presenta una sinopsis taxonómica, que incluye descripciones de las especies, una clave para su determinación y mapas de distribución en el estado. Se complementa la información con datos sobre fenología, distribución altitudinal y tipos de vegetación donde se encuentran las especies en Morelos. 

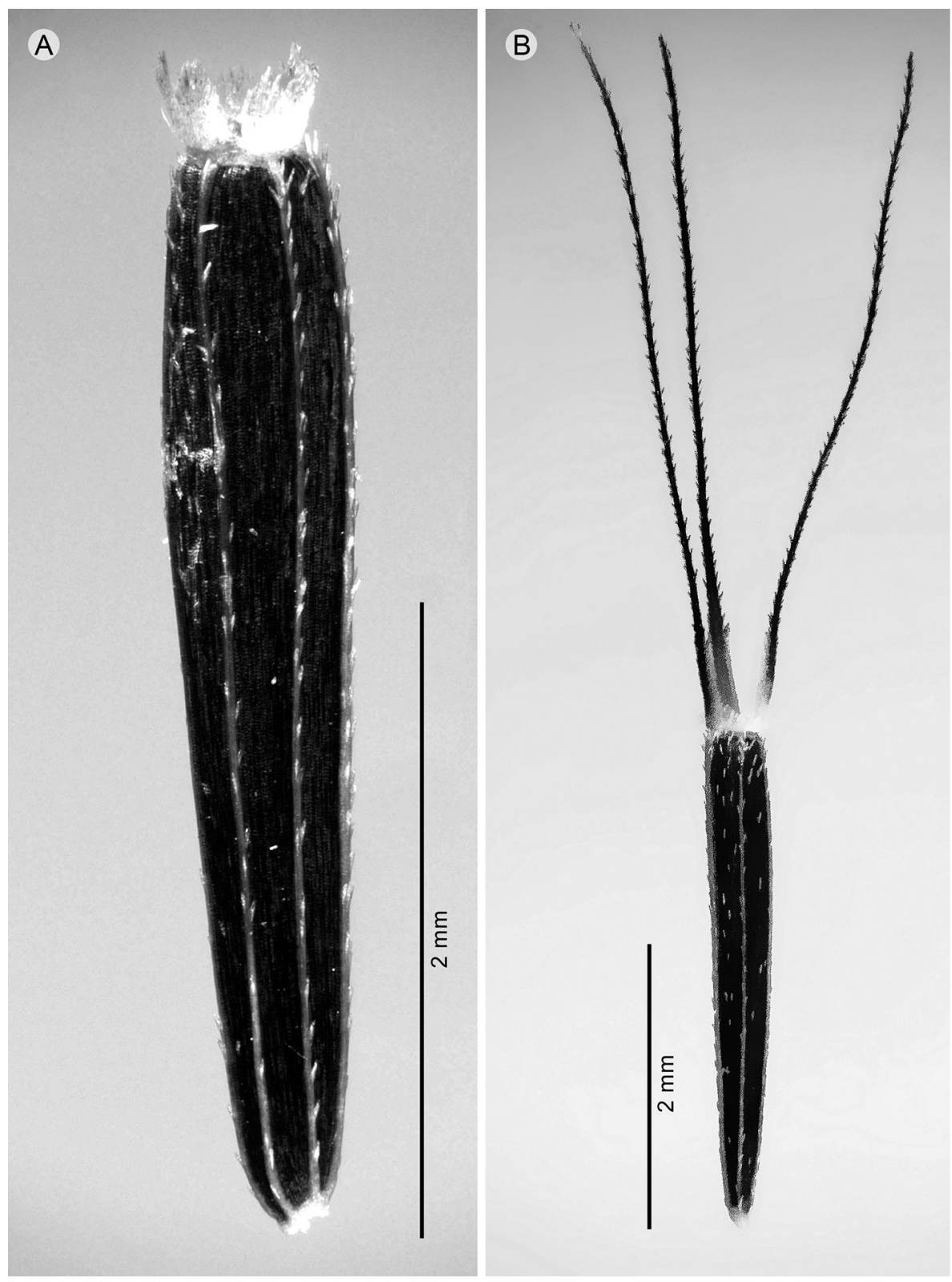

C

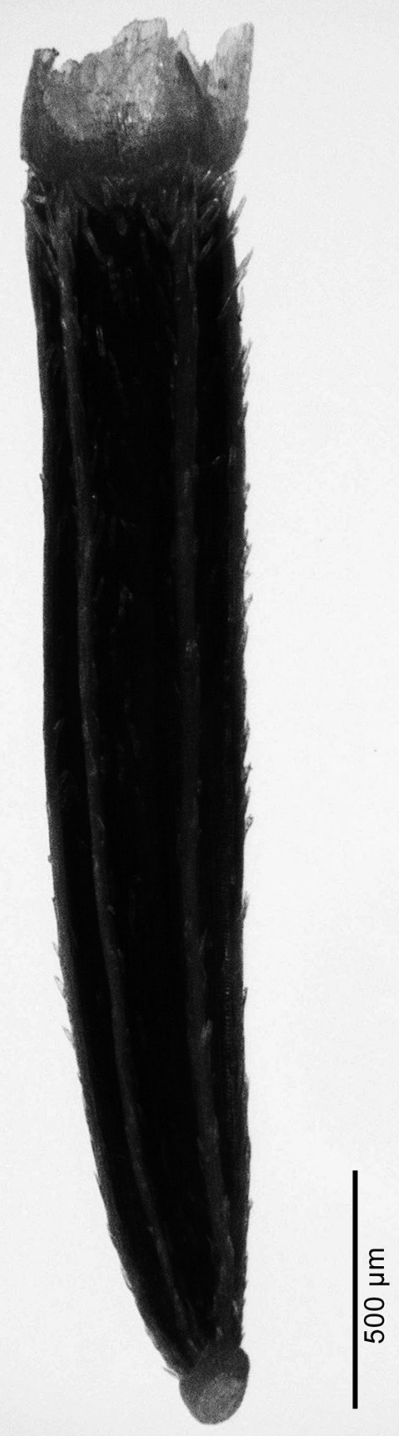

Figura 1: A, B. Stevia aschenborniana Sch. Bip., aquenios heteromorfos. A. idiocarpo con vilano de escamas; B. adelfocarpo con vilano de aristas alternando con escamas; C. Stevia jorullensis Kunth aquenio isomorfo con vilano coroniforme.

\section{Materiales y Métodos}

Se revisaron y estudiaron 252 especímenes del género Stevia recolectados en el estado de Morelos, los cuales representan 201 registros únicos. De ellos, 177 ejemplares de herbario están depositados en la colección del Herbario Nacional de México (MEXU) del Instituto de Biología, Universidad Nacional Autónoma de México (UNAM). Además, se revisaron 75 especímenes adicio- nales del género depositados en otros herbarios nacionales (ENCB, HUMO, IEB, SLPM, XAL) y del extranjero (LL, MO, TEX). Dichos especímenes fueron analizados y examinados cuidadosamente bajo el microscopio estereoscópico (Olympus SZ60, Tokyo, Japón) para elaborar las descripciones morfológicas y seleccionar aquellos caracteres de utilidad para la identificación de las especies. Con la información recopilada se elaboró una clave para 
la identificación de los taxones dentro del estado y las descripciones del género y las especies. Igualmente, se tomaron muestras de los aquenios de un par de especies; una de ellas con aquenios heteromorfos (Stevia aschenborniana Sch. Bip.) y otra con aquenios isomorfos (Stevia jorullensis Kunth). Posteriormente, estos aquenios se observaron en el microscopio especializado (Zeiss Axio Zoom V16, Göttingen, Alemania) y fotografiaron (cámara AxioCam MRc5, Zeiss, Göttingen, Alemania) en el Laboratorio de Microscopía y Fotografía de la Biodiversidad del Instituto de Biología de la UNAM (Fig. 1). Los aquenios de $S$. aschenborniana se tomaron del ejemplar A. Ramírez 912 y los de $S$. jorullensis de P. Tenorio 21339, ambos depositados en MEXU. Por otro lado, a partir de la información de las etiquetas de herbario, se sintetizaron los datos sobre tipo de vegetación donde se les encontró, tiempos de floración y su distribución en el estado. Las localidades de recolecta se georreferenciaron para elaborar los mapas de distribución de cada especie en Morelos. Los mapas se realizaron usando el programa ArcGIS 10.0 (ESRI, 2010).

\section{Resultados}

La revisión del material herborizado permitió la identificación de 25 especies de Stevia en el estado de Morelos, cinco de las cuales están representadas por variedades morfológicas. La mayoría de las especies (21) son plantas herbáceas, tanto anuales como perennes; solamente cuatro de ellas presentan algun grado de lignificación, ya sea con hábito sufruticoso o arbustivo.

El mayor número de especies se reporta del bosque de pino-encino (21); otro conjunto importante se ha registrado del bosque de encino (10). Varias especies toleran ambientes más termófilos, siendo además encontradas en zonas de baja altitud con bosque tropical estacionalmente seco (ocho). Por otra parte, ocho especies se registran de ambientes antrópicamente perturbados, ya sea como ruderales ( $S$. aschenborniana, S. purpusii B.L. Rob., S. salicifolia Cav., S. serrata Cav., S. subpubescens Lag. y $S$. triflora DC.) o arvenses (S. salicifolia, S. suaveolens Lag. y $S$. viscida Kunth).
En el Apéndice 1 se mencionan los nombres que la literatura reporta como sinónimos de los nombres aceptados en este trabajo (Grashoff, 1972; Turner, 1997), además de algunas especies que fueron excluidas por no considerarlas parte de la flora del estado, consistiendo principalmente en identificaciones erróneas. Por otra parte, en el Apéndice 2 se incluyen algunas especies que se sospecha pudieran existir en Morelos, pero que hasta la fecha no se han observado especímenes que documenten fehacientemente su presencia.

\section{TAXONOMÍA}

Stevia Cav., Icon. 4: 32. 1797.

TIPO: Stevia salicifolia Cav. = Metastevia Grashoff, Brittonia 27: 69. 1975.

Hierbas anuales, con raíces primarias o perennes rizomatosas con raíces fasciculadas, sufrútices o arbustos; tallos erectos, a veces decumbentes, simples o ramificados, ramas superiores ascendentes a divaricadas, opuestas o alternas, teretes, color verdoso, parduscos o violáceorojizos, ligeramente estriados, con indumento piloso, hirsuto o estrigoso, a veces velutino o tomentoso, muchas veces con glándulas estipitadas, en ocasiones glabros o glabrescentes; hojas opuestas o alternas, distribuidas a lo largo del tallo, o a veces más o menos restringidas a la porción basal, pecioladas o sésiles, lámina por lo general simple, ovada a deltada, a veces lanceolada a linearlanceolada, elíptica u obovada o espatulada, ápice agudo a obtuso, margen entero a dentado, aserrado, o crenado, raras veces profundamente pinnatífido, base obtusa a cuneada, a veces decurrente sobre el pecíolo o formando una base pecioliforme, en ocasiones truncada a subcordada, color verdoso a veces morado o violáceo-rojiza, superficie adaxial glabra o con indumento piloso, hirsuto o estrigoso, a veces punteada con glándulas resinosas, subsésiles o con glándulas estipitadas, en ocasiones glutinosa, lustrosa o vernicosa, superficie abaxial glabra o más frecuentemente con indumento piloso, hirsuto o estrigoso, 
a veces velutino a densamente tomentoso, a menudo punteada con glándulas resinosas, subsésiles, ocasionalmente con glándulas estipitadas, a veces glutinosa, lustrosa o vernicosa, triplinervada, ocasionalmente trinervada, las venas terciarias y de mayor orden formando una retícula, a veces muy resaltada, herbácea, a veces coriácea o membranosa; cabezuelas homógamas, discoides, dispuestas en grupos corimbiformes o glomerulares, compactos y densos, o paniculiformes, amplios y laxos, pedúnculos pilosos, estrigosos, hírtulos, velutinos o tomentosos, a menudo con glándulas estipitadas o punteado con glándulas resinosas, subsésiles, o ambas, raras veces glabro; involucro cilíndrico, uniseriado, formado por 5 brácteas iguales o subiguales, enteras o con bordes sinuosos poco profundos y desiguales, lineares a oblongas, agudas a obtusas en el ápice, glabras a estrigosas o pilosas, en ocasiones glandular-estipitadas o punteado con glándulas resinosas, subsésiles, herbáceas a cartáceas, color verdoso, frecuentemente morado o violáceo-rojizas en el ápice; receptáculo plano a ligeramente convexo, desnudo; flores 5 por cabezuela, perfectas, fértiles, corolas estrechamente infundibuliformes, pentámeras, con 5 lóbulos apicales, iguales o desiguales en longitud, color blanco, rosadas, violáceo-rojizas o moradas, a menudo el tubo y la garganta morados o violáceo-rojizos y los lóbulos blancos o rosado pálidos, glabras o con el tubo piloso, lóbulos a menudo pilosos en la superficie abaxial, garganta con un anillo piloso o de glándulas resinosas, subsésiles en la superficie adaxial; anteras obtusas en la base, apendiculadas, apéndices escariosos, a menudo elípticos u ovado-oblongos; ramas del estilo filiformes, largas, exertas, obtusas, generalmente papilosas; aquenios columnares a fusiformes, pentagonales, heteromorfos o isomorfos, glabros o frecuentemente hispidulosos, especialmente en las costillas y en el ápice, a veces punteados con glándulas resinosas, subsésiles; vilano de escamas translúcidas, libres o unidas en una corona conspicua o muy reducida, a menudo erosas o laceradas, por lo general con 1-5 aristas, aladas en la base, muchas veces color violáceo, en ocasiones solo aristas con la base alada amplia, muy rara vez ausente.
Género con unas 250 especies distribuidas desde el sur de Estados Unidos de América hasta Argentina y Brasil. En México se reconocen 116 especies, 25 de ellas del estado de Morelos; más de 90\% de las especies (107) restringen su distribución a México y de estas endémicas del territorio nacional, 17 se registran en el estado.

\section{Clave para la identificación de las especies de Stevia en el estado de Morelos}

1a. Hierbas anuales o perennes ..................................... 2

1b. Sufrútices o arbustos .......................................... 23

2a. Cabezuelas dispuestas en grupos paniculiformes, amplios y laxos, pedunculadas (pedúnculos 5-30 $\mathrm{mm}$ de largo); lóbulos de la corola desiguales en forma y tamaño

2b. Cabezuelas dispuestas en grupos corimbiformes a glomerulares, compactos y densos, sésiles o subsésiles; lóbulos de la corola iguales o casi iguales en tamaño o forma

3a. Hojas alternas, formando fascículos distribuidos a lo largo del tallo S. viscida Kunth

3b. Hojas opuestas (a veces alternas sólo cerca de la inflorescencia)

4a. Hierbas perennes, rizomatosas

S. micradenia B.L. Rob.

4b. Hierbas anuales, con raíz primaria 5

5a. Hojas por lo general 3-lobuladas, lóbulos lineares a oblongos S. trifida Lag.

5b. Hojas no lobuladas, ovadas a subrómbicas u ovadodeltadas S. aschenborniana Sch. Bip.

6a. Hojas opuestas (a veces alternas sólo cerca de la inflorescencia) 7

6b. Hojas alternas o en fascículos alternos a lo largo del tallo

7a. Hojas sésiles, lineares a oblongas o angostamente lanceoladas a oblanceoladas, por lo general connatas en la base S. connata Lag.

7b. Hojas pecioladas (en ocasiones el pecíolo muy corto, pero nunca evidentemente sésiles), a veces el pecíolo alado, si pareciendo sésiles, entonces elípticas a ovadas 8 
8a. Involucro y/o pedúnculos con glándulas estipitadas 9

8b. Involucro y/o pedúnculos sin glándulas estipitadas, a veces punteados con glándulas resinosas, subsésiles 12

9a. Aquenios glabros .................. S. monardifolia Kunth

9b. Aquenios hispídulos, al menos en el ápice ........... 10

10a. Superficie abaxial de las hojas puberulenta a tomentulosa; pedúnculos sin glándulas estipitadas

S. purpusii B.L. Rob.

10b. Superficie abaxial de las hojas puberulenta a esparcidamente hirsuta o pilosa; pedúnculos con glándulas estipitadas ..... 11

11a. Ramas superiores divaricadas; aquenios por lo general heteromorfos, el vilano de los adelfocarpos de aristas y escamas, el de los idiocarpos coroniforme (raras veces isomorfos y el vilano de aristas con escamas, o coroniforme) ................ S. caracasana DC.

11b. Ramas superiores ascendentes; aquenios con vilano de escamas libres o coroniforme

S. incognita Grashoff

12a. Hojas confinadas a la mitad o al tercio inferior de la planta 13

12b. Hojas distribuidas a lo largo del tallo 14

13a. Tallo ascendente a ligeramente decumbente; hojas todas pecioladas, ovadas a deltadas, aplanadas; aquenios heteromorfos, los adelfocarpos con aristas y escamas S. deltoidea Greene

13b. Tallo erecto; hojas superiores sésiles, las inferiores pecioladas, elípticas a ovadas, conduplicadas; aquenios isomorfos, sin aristas S. iltisiana Grashoff

14a. Superficie abaxial de las hojas pilósula a tomentosa 15

14b. Superficie abaxial de las hojas glabra a estrigulosa o estrigosa 16

15a. Hojas romboideas a ovado-lanceoladas, el indumento de la superficie abaxial color blanquecino a grisáceo S. suaveolens Lag.

15b. Hojas ovadas, rara vez lanceolado-elípticas, el indumento de la superficie abaxial color amarillento ........ S. triflora DC. 16a. Involucro estriguloso a estrigoso S. origanoides Kunth

16b. Involucro glabro a puberulento 17

17a. Corolas color blanco 18

17b. Corolas color violáceo a violáceo-rojizas o moradas 19

18a. Hojas glabras o glabrescentes en ambas superficies (aunque punteadas con glándulas resinosas), las venas formando una retícula notablemente resaltada en ambas superficies ... S. scabrella Benth. var. scabrella

18b. Hojas puberulentas a pilosas (también punteadas con glándulas resinosas, subsésiles), las venas sin formar una retícula resaltada ........S. ovata Willd. var. ovata

19a. Hojas ovadas, algunas veces elípticas, deltadas o lanceoladas, nunca conduplicadas, por lo general pecioladas, todas opuestas ............ S. jorullensis Kunth

19b. Hojas oblanceoladas, sésiles a subsésiles, conduplicadas, las superiores alternas

S. clinopodioides Greenm.

20a. Corolas color blanco 21

20b. Corolas color violáceo a violáceo-rojizas o moradas .. 22

21a. Hojas con la superficie abaxial tomentosa, las venas de la superficie abaxial formando una retícula resaltada S. hypomalaca B.L. Rob.

21b. Hojas con la superficie abaxial glabrescente a pilosa, las venas de la superficie abaxial sin formar una retícula resaltada S. serrata Cav. var. serrata

22a. Involucro con glándulas estipitadas; aquenios heteromorfos, los adelfocarpos con 3 aristas

S. eupatoria (Spreng.) Willd.

22b. Involucro sin glándulas estipitadas; aquenios isomorfos, sin aristas S. pilosa Lag.

23a. Lóbulos de la corola glabros en la superficie abaxial 24

23b. Lóbulos de la corola pubescentes en la superficie abaxial 25

24a. Aquenios isomorfos, con vilano de aristas; tallos glabros, verrucosos; hojas pecioladas, glabras (aunque punteadas con glándulas resinosas), vernicosas S. vernicosa Greenm. 
24b. Aquenios heteromorfos o isomorfos, cuando isomorfos, el vilano coroniforme, sin aristas; tallos puberulentos a glabrescentes, no verrucosos; hojas sésiles a subsésiles, esparcidamente pilosas en las venas de ambas superficies y en el margen (también punteadas con glándulas resinosas), glutinosas

S. salicifolia Cav. var. salicifolia

25a. Superficie abaxial de las hojas glabra (aunque punteada con glándulas resinosas); venas de las hojas formando una retícula notablemente resaltada en ambas superficies ... S. scabrella Benth. var. scabrella 25b. Superficie abaxial esparcidamente puberulenta a tomentulosa a lo largo de las venas (también punteada con glándulas resinosas); venas de las hojas sin formar una retícula resaltada

S. subpubescens Lag. var. subpubescens

1. Stevia aschenborniana Sch. Bip., Linnaea 25: 269. 1853. TIPO: MÉXICO. Localidad desconocida, 13.II.1842, A. Aschenborn 652 (holotipo: P00704301!).

Hierbas anuales, con raíces fibrosas, 0.3-1.5 m de alto; tallo erecto, con glándulas estipitadas, las ramas superiores ascendentes, opuestas; hojas opuestas, distribuidas a lo largo del tallo, pecioladas, lámina ovada a subrómbica u ovado-deltada, $2-5.5 \mathrm{~cm}$ de largo, 0.8-4 $\mathrm{cm}$ de ancho, margen aserrado a crenado, ápice agudo a obtuso, base truncada a cuneada, ambas superficies glabras a esparcidamente pilosas y punteadas con glándulas resinosas, subsésiles, triplinervada, alada, $0.5-3 \mathrm{~cm}$ de largo; cabezuelas dispuestas en grupos paniculiformes, amplios y laxos, pedúnculos 5-20 $\mathrm{mm}$ de largo, con glándulas estipitadas; involucro 4.5-6.5 mm de largo, piloso, por lo general con glándulas estipitadas; corolas 6-10 mm de largo, tubo y garganta color violáceo-rojizos a morados, lóbulos desiguales en forma y tamaño, color blanco, pilosos en la superficie abaxial; aquenios 2.5-4.5 $\mathrm{mm}$ de largo, hispidulosos, heteromorfos; vilano de los adelfocarpos 3-4 aristas, 4-5.5 mm de largo, escamas, $0.1 \mathrm{~mm}$ de largo, el de los idiocarpos de escamas libres, 0.2-0.4 mm de largo.
Hábitat: bosque de Pinus-Quercus, Quercus y tropical caducifolio, ruderal.

Intervalo altitudinal: 1600-2290 m.

Floración: octubre a diciembre.

Distribución en México: Chihuahua, Coahuila, Estado de México, Guerrero, Jalisco, Michoacán, Morelos, Nayarit, Oaxaca, Puebla, Querétaro y Sinaloa.

Distribución en Morelos: principalmente al norte del estado; también al centro y suroeste (Fig. 2).

Ejemplares examinados: MÉXICO. Morelos, municipio Cuernavaca, km 61 autopista México - Cuernavaca, 2100 m, 20.X.1963, E. Matuda 37345 (MEXU); campos de lava cerca de Cuernavaca, 2250 m, 4.XI.1900, C. G. Pringle 9120 (MEXU). Municipio Emiliano Zapata, cerro cercano al pueblo de Tepetzingo, $1567 \mathrm{~m}$, 5.XI.1997, A. Ramírez 912 (MEXU). Municipio Tepoztlán, $2.97 \mathrm{~km}$ con orientación $80.88^{\circ}$ de la iglesia de Tepoztlán, 1919 m, 12.XI.2011, S. Block 1269 (MEXU); Paraje "El Tezcal", Santa Catarina, 1600 m, 4.XI.1985, E. Dávila s.n. (MEXU); Paraje Chicuacemac, cerca de Atongo, 1850 m, 30.X.1987, M. L. Espín 368 (HUMO); Paraje Texcal, Santa Catarina, 1650 m, 4.XI.1987, M. L. Espín 383 (ENCB, MEXU); alrededores de la Estación El Parque, 2300 m, 10.XI.1967, J. Flores 216 (ENCB, LL); Meztitla cerca del campo de entrenamiento de los Boy Scouts, 1750 m, 11.XI.1982, J. García 1718 (ENCB, MEXU, SLPM); km 61 autopista México - Cuernavaca, 2100 m, s.f., D. B. Gold 256 (ENCB, MEXU); Tepoztlán a Santo Domingo, L. Paray 1298 (ENCB, MEXU); San Juan Tlacotenco, 2320 m, 15.III.1998, T. Yahara 1305 (MEXU); above Tepoztlán, T. Yahara 2020 (MEXU); a lo largo de la carretera $115 \mathrm{D}$ cerca de la salida a Tepoztlán, 1680 m, 1.XII.2003, T. Yahara 2882 (MEXU); Tlacotenco, 2225 m, 2.XII.2003, T. Yahara 2884 (MEXU), 2895 (MEXU). Municipio Tlayacapan, barranca Tepecapa, 1920 m, 13.XI.2009, R. Hernández 97 (HUMO). 


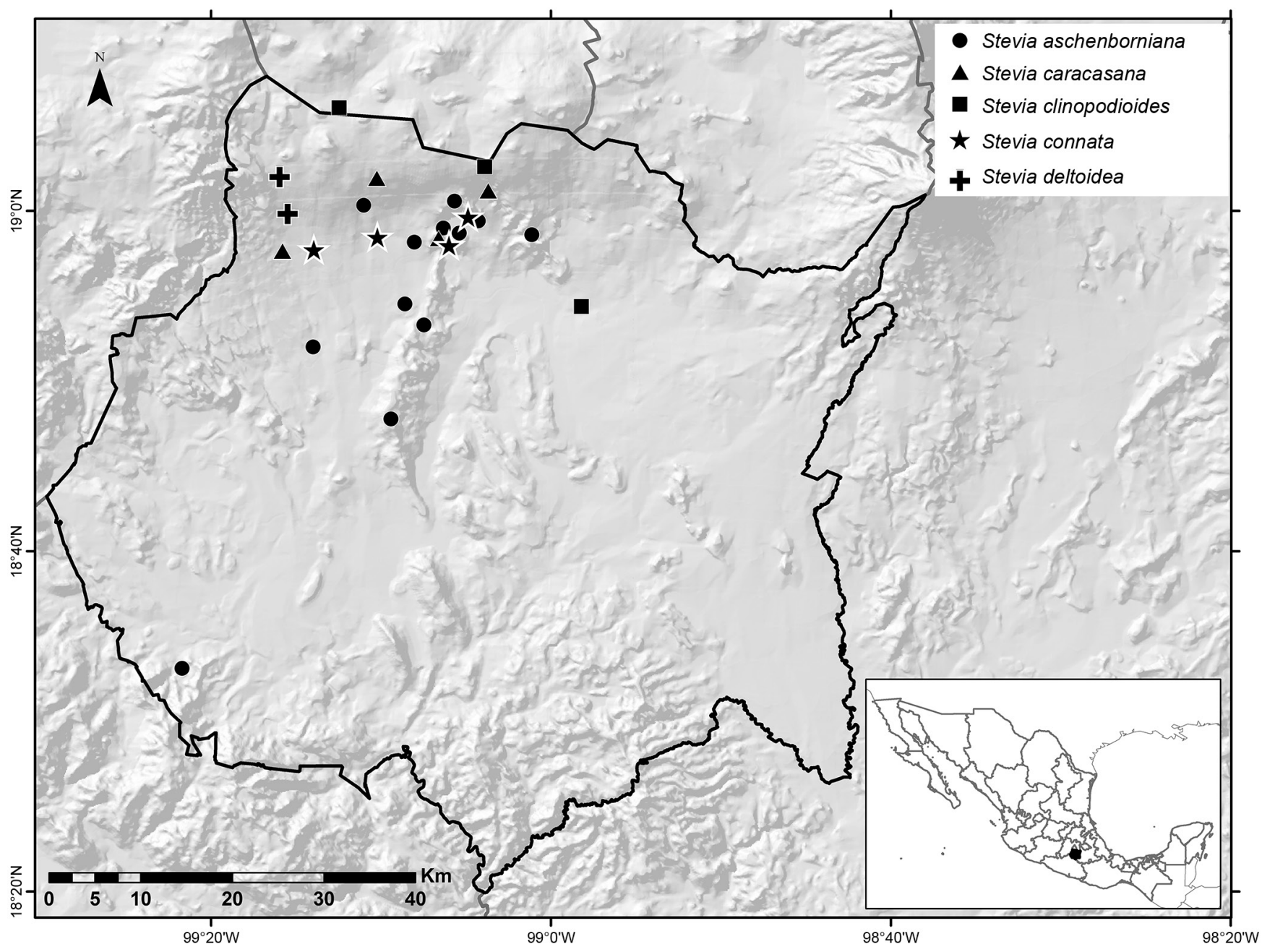

Figura 2: Distribución de Stevia aschenborniana Sch. Bip., S. caracasana DC., S. clinopodioides Greenm., S. connata Lag. y S. deltoidea Greene en el estado de Morelos.

2. Stevia caracasana DC., Prodr. 5: 119. 1836. TIPO: VENEZUELA. Caracas, 1829, J. M. Vargas 108 (holotipo: G-DC00465278!).

Hierbas perennes, rizomatosas, con raíces fasciculadas, 1-1.5 m de alto; tallo erecto, puberulento a esparcidamente piloso y con glándulas estipitadas, ramas superiores divaricadas, opuestas; hojas opuestas, distribuidas a lo largo del tallo, pecioladas, lámina ovada, raras veces lanceolada o elíptica, 2-10(-15) cm de largo, 2-5(-8) cm de ancho, margen aserrado, crenado o dentado, ápice agudo a obtuso, base generalmente truncada a cuneada, gla- bras a pilosas, el indumento color blanquecino, superficie abaxial puberulenta a esparcidamente pilosa, punteada con glándulas resinosas, subsésiles, triplinervada, pecíolo alado, 0.5-3 cm de largo; cabezuelas dispuestas en grupos corimbiformes, compactos y densos, pedúnculos 2-5 mm de largo, con glándulas estipitadas; involucro 4.5-7 mm de largo, con glándulas estipitadas; corolas 4-7 mm de largo, tubo y garganta color violáceo-rojizos a morados, lóbulos iguales o casi iguales en tamaño o forma, color blanco, pilosos en superficie abaxial; aquenios 3.5-4.5 $\mathrm{mm}$ de largo, hispidulosos, por lo general heteromorfos; vilano de los adelfocarpos, 3-4(5) aristas, 5-8 mm de lar- 
go, escamas, $0.1 \mathrm{~mm}$ de largo, el de los idiocarpos coroniforme, 0.1-0.3 mm de largo, raras veces isomorfos con vilano de aristas con escamas, o coroniforme.

Hábitat: bosque de Pinus-Quercus y tropical caducifolio.

Intervalo altitudinal: $300-3000 \mathrm{~m}$.

Floración: diciembre a marzo.

Distribución en México: Chiapas, Ciudad de México, Colima, Durango, Estado de México, Guerrero, Jalisco, Michoacán, Morelos, Nayarit, Oaxaca, Puebla, Querétaro, San Luis Potosí, Sinaloa, Sonora, Tamaulipas, Veracruz y Zacatecas.

Distribución en Morelos: norte y noroeste del estado (Fig. 2).

Ejemplares examinados: MÉXICO. Morelos, municipio Cuernavaca, $\mathrm{N}$ de la barranca de Atzingo, 1700 m, 25.XI.1987, E. Estrada 1883 (MEXU). Municipio Tepoztlán, 500 m de Santo Domingo Ocotitlán, 2000 m, 18.XI.1987, M. L. Espín 424 (MEXU); cerro del Chalchi, Tepoztlán, 1800 m, 12.XI.1988, M. L. Espín 604 (ENCB, MEXU); entre Santa Catarina y Ahuatepec, $R$. Medina 162 (MEXU).

3. Stevia clinopodioides Greenm., Proc. Amer. Acad. Arts. 32: 307. 1897. TIPO: MÉXICO. Ciudad de México, Serranía de Ajusco, 2896 m, 22.X.1896, C. G. Pringle 6594 (holotipo: GH00012716!, isotipos: AC00319555!, BR0000005522880!, CAS0004683!, CM2548!, E00413744!, ENCB003068!, F0051490F!, GOET002049!,JE00004586!, K000488685!, M0029519!, MEXU!, MIN1002531!, MO191373!, MSC0092899!, NDG52773!, NY00260081!, P00704317!, S06-21181!, TEX00000395!, UC86434!, US00146017!, VT027799!).

Hierbas perennes, rizomatosas, con raíces fasciculadas, 0.1-0.45 $\mathrm{m}$ de alto; tallo erecto, puberulento a densamente pubescente, ramas superiores ascendentes, alternas; hojas opuestas, las superiores alternas, distribuidas a lo largo del tallo, subsésiles, el pecíolo muy corto, pero nunca evidentemente sésiles, lámina oblanceolada, conduplicada, $1.5-4.5 \mathrm{~cm}$ de largo, $0.5-1.2 \mathrm{~cm}$ de ancho, margen crenado, ápice obtuso, base cuneada, glabra a esparcidamente pilosa, sobre todo en el margen $\mathrm{y}$ en las venas, indumento color blanquecino, punteada en ambas superficies con glándulas resinosas, triplinervadas; cabezuelas dispuestas en glomérulos, pedúnculos 2-4 $\mathrm{mm}$ de largo, puberulentos; involucro 6-8 $\mathrm{mm}$ de largo, piloso; corolas 3.5-5 mm de largo, color morado o violáceo-rojizas, lóbulos iguales o casi iguales en tamaño o forma, pilosos en superficie abaxial; aquenios 3-3.5 mm de largo, esparcidamente hispidulosos hacia el ápice, isomorfos; vilano coroniforme, 0.2-0.4 mm de largo, raras veces uno de los aquenios con 1-2 aristas, hasta $3 \mathrm{~mm}$ de largo.

Hábitat: bosque de Pinus y de Pinus-Quercus.

Intervalo altitudinal: 3000-3100 m.

Floración: julio a octubre.

Distribución en México: Ciudad de México, Estado de México, Michoacán, Morelos y Veracruz.

Distribución en Morelos: norte y noreste del estado (Fig. 2).

Ejemplares examinados: MÉXICO. Morelos, municipio Huitzilac, $6 \mathrm{~km} \mathrm{~N}$ of Tres Cumbres, C. $G$. Lyons Jr. 120 (MEXU). Municipio Tepoztlán, Santo Domingo Ocotitlán, 2950 m, 21.X.1987, M. L. Espín 301 (ENCB, MEXU, TEX). Municipio Yautepec, Oaxtepec, 31.VIII.1952, F. Gallegos 403 (MEXU).

4. Stevia connata Lag., Gen. Sp. P1. 27. 1816. TIPO: MÉXICO. México, s.f., anónimo s.n. (holotipo: probablemente MA, no visto). 
Hierbas perennes, rizomatosas, con raíces fasciculadas, 0.5-2 m de alto; tallo erecto, glabro a esparcidamente puberulento, ramas superiores ascendentes, opuestas; hojas opuestas, distribuidas a lo largo del tallo, sésiles, lámina linear-oblonga a estrechamente lanceolada, a menudo conduplicada y curvado-reflexa, 4.5-11 $\mathrm{cm}$ de largo, 0.8-1.3 cm de ancho, margen crenado a serrado, ápice agudo, base por lo general connata, a veces atenuada a truncada, glabra, aunque la superficie abaxial punteada con glándulas resinosas, subsésiles, trinervada, tres venas principales casi paralelas al margen, resaltadas en superficie abaxial; cabezuelas dispuestas en grupos corimbiformes, compactos y densos, pedúnculos 0.5-10 $\mathrm{mm}$ de largo, pilosos; involucro 4.5-6 $\mathrm{mm}$ de largo, glabro a puberulento; corolas 6-10 mm de largo, color blanco, lóbulos iguales o casi iguales en tamaño o forma, glabros en superficie abaxial; aquenios 2.5-3.7 $\mathrm{mm}$ de largo, hispidulosos, heteromorfos; vilano de los adelfocarpos, 3 aristas, 4-5 $\mathrm{mm}$ de largo, escamas, 0.5 $\mathrm{mm}$ de largo, el de los idiocarpos de escamas libres, 0.3$0.7 \mathrm{~mm}$ de largo.

Hábitat: bosque de Quercus y tropical caducifolio.

Intervalo altitudinal: $610-2450 \mathrm{~m}$.

Floración: agosto a noviembre.

Distribución en México: Estado de México, Guerrero, Michoacán, Morelos, Oaxaca y Puebla.

Distribución en Morelos: norte y noroeste del estado (Fig. 2).

Ejemplares examinados: MÉXICO. Morelos, municipio Cuernavaca, $2 \mathrm{~km}$ después de la entrada a Cuernavaca, entrando por la autopista México - Cuernavaca, XI.1981, A. Ortega 90 (MEXU). Municipio Tepoztlán, km 15 carretera Cuernavaca - Tepoztlán, 1670 m, 18.X.1987, M. L. Espin 292 (ENCB, MEXU); Sierra Chalchi, al S de Tepoztlán, ladera N, 20.X.1946, F. Miranda 3797
(MEXU); cerro Chalchi, cerca de Tepoztlán, VIII.1955, L. Paray 1725 (ENCB, MEXU).

5. Stevia deltoidea Greene, Pittonia 3: 31. 1896. TIPO: MÉXICO. Oaxaca, Sierra de San Felipe, 6.X.1894. C. G. Pringle 4976 (holotipo: GH00012720!, isotipos: BR0000005533909!, CM2550!, MEXU!, MSC0092903!, NDG52775!,NY00260084!,RSA0001601!, TEX00373447!, UC86465!, US00146020!).

Hierbas perennes, rizomatosas, con raíces fasciculadas, 0.5-0.8 m de alto; tallo ascendente a ligeramente decumbente, puberulento a piloso, ramas superiores ascendentes, opuestas; hojas opuestas, en su mayor parte confinadas a la mitad o al tercio inferior de la planta, pecioladas, lámina ovada a deltada, 2.5-4.5 cm de largo, 1.5-4 $\mathrm{cm}$ de ancho, margen crenado, ápice obtuso a redondeado, base obtusa a cuneada, superficie adaxial glabra a esparcidamente pilosa, indumento color blanquecino, a veces punteada con glándulas resinosas, superficie abaxial pilosa, principalmente a lo largo de las venas, punteada con glándulas resinosas, triplinervada, pecíolo alado, piloso, 1-2.5(-4.5) cm de largo; cabezuelas dispuestas en grupos corimbiformes, compactos y densos, pedúnculos 5-20 mm de largo, puberulentos; involucro 3.5-6 mm de largo, puberulento; corolas 5-6 mm de largo, color morado, lóbulos iguales o casi iguales en tamaño o forma, pilosos en superficie abaxial; aquenios 2.5-3.5 mm de largo, hispidulosos en el ápice, heteromorfos; vilano de los adelfocarpos, 3 aristas, 4-5 mm de largo, escamas, 0.4-0.5 mm de largo, el de los idiocarpos coroniforme, $0.5 \mathrm{~mm}$ de largo.

Hábitat: bosque de Pinus-Quercus, Quercus y tropical caducifolio.

Intervalo altitudinal: $1800-2600 \mathrm{~m}$.

Floración: octubre a noviembre.

Distribución en México: Aguascalientes, Ciudad de México, Estado de México, Guanajuato, Guerrero, 
Hidalgo, Jalisco, Michoacán, Morelos, Oaxaca, Puebla, Querétaro, Tlaxcala y Veracruz.

Distribución en Morelos: sólo conocida por un par de recolectas al noroeste del estado (Fig. 2).

Ejemplares examinados: MÉXICO. Morelos, municipio Cuernavaca, carretera México - Cuernavaca km 53, 2450 m, 25.X.1959, J. Espinosa 221b (MEXU); Cuernavaca, 2050 m, 7.XI.1969, G. B. Hinton 17456Bis (MEXU).

Turner (1997) utilizó el nombre de Stevia hirsuta DC. (publicado en octubre de 1836) como el nombre correcto para esta especie. Sin embargo, S. hirsuta es un homónimo de $S$. hirsuta Hook. \& Arn. (publicada en marzo de 1836), la cual es una especie sudamericana.

6. Stevia eupatoria (Spreng.) Willd., Sp. P1. 3: 1775. 1804. TIPO: desconocido.

Hierbas perennes, rizomatosas, con raíces fasciculadas, 0.2-0.8 m de alto; tallo erecto, estrigoso a puberulento, con glándulas estipitadas, ramas superiores ascendentes, alternas; hojas alternas o en fascículos alternos dispuestos a lo largo del tallo, sésiles, lámina linear-oblonga a estrechamente oblanceolada, $1.2-3.7 \mathrm{~cm}$ de largo, 3-8 cm de ancho, margen entero a serrado, ápice obtuso, base obtusa a cuneada, estrigoso-puberulenta a pilosa, punteada en ambas superficies con glándulas resinosas, subsésiles, triplinervada; cabezuelas dispuestas en grupos corimbiformes, compactos y densos, pedúnculos $4 \mathrm{~mm}$ de largo, puberulentos, con glándulas estipitadas; involucro 5-7 mm de largo, con glándulas estipitadas y glándulas resinosas, subsésiles; corolas 5-6.5 mm, color violáceo, lóbulos iguales o casi iguales en tamaño o forma, pilosos en superficie abaxial; aquenios 3-4 mm de largo, hispidulosos en el ápice, heteromorfos; vilano de los adelfocarpos, 3 aristas, 3-6 mm de largo, escamas, 0.5-1.5 $\mathrm{mm}$ de largo, el de los idiocarpos de escamas libres, 0.5$1.5 \mathrm{~mm}$ de largo.
Hábitat: bosque de Pinus-Quercus.

Intervalo altitudinal: 2350-2900 m.

Floración: julio a noviembre.

Distribución en México: Ciudad de México, Estado de México, Guanajuato, Hidalgo, Michoacán, Morelos, Nayarit, Nuevo León, Puebla, Querétaro, San Luis Potosí, Tlaxcala y Veracruz.

Distribución en Morelos: sólo conocida por una recolecta al norte del estado (Fig. 3).

Ejemplares examinados: MÉXICO. Morelos, municipio Tepoztlán, Tepozteco, 19.IX.1938, E. Lyonnet 2537 (MEXU).

7. Stevia hypomalaca B.L. Rob., Contr. Gray Herb. 90: 13. 1930. TIPO: MÉXICO. Morelos, mountain side above Cuernavaca, 1981 m, 2.X.1896, C. G. Pringle 6603 (holotipo: GH00012730!, isotipos: BR0000005533589!, E00413738!, F0051497F!, JE00004472!, K000488693!, MEXU!, MO191370!, NDG52768!, NY00260090!, P00704251!, S0621179!, TEX00373450!, UC86457!, US00146039!).

Hierbas perennes, rizomatosas, con raíces fasciculadas, $0.4-1.5 \mathrm{~m}$ de alto; tallo erecto, tomentoso, ramas superiores ascendentes, alternas; hojas alternas o en fascículos alternos dispuestos a lo largo del tallo, sésiles, lámina oblanceolada a espatulada, reflexa, 1.3-3.5 cm de largo, 0.4-1 $\mathrm{cm}$ de ancho, margen entero a crenado, ápice obtuso, base atenuada, superficie adaxial densamente pilosa, superficie abaxial tomentosa, indumento color blanquecino a grisáceo, con glándulas resinosas, subsésiles debajo del indumento, triplinervada, venas de superficie abaxial formando una retícula notablemente resaltada; cabezuelas en grupos corimbiformes, compactos y densos, pedúnculos 2-15 mm de largo, vilosos; involucro $4.5 \mathrm{~mm}$ de largo, tomentoso; corolas $7 \mathrm{~mm}$ de largo, color blanco, lóbulos iguales o casi iguales en tama- 


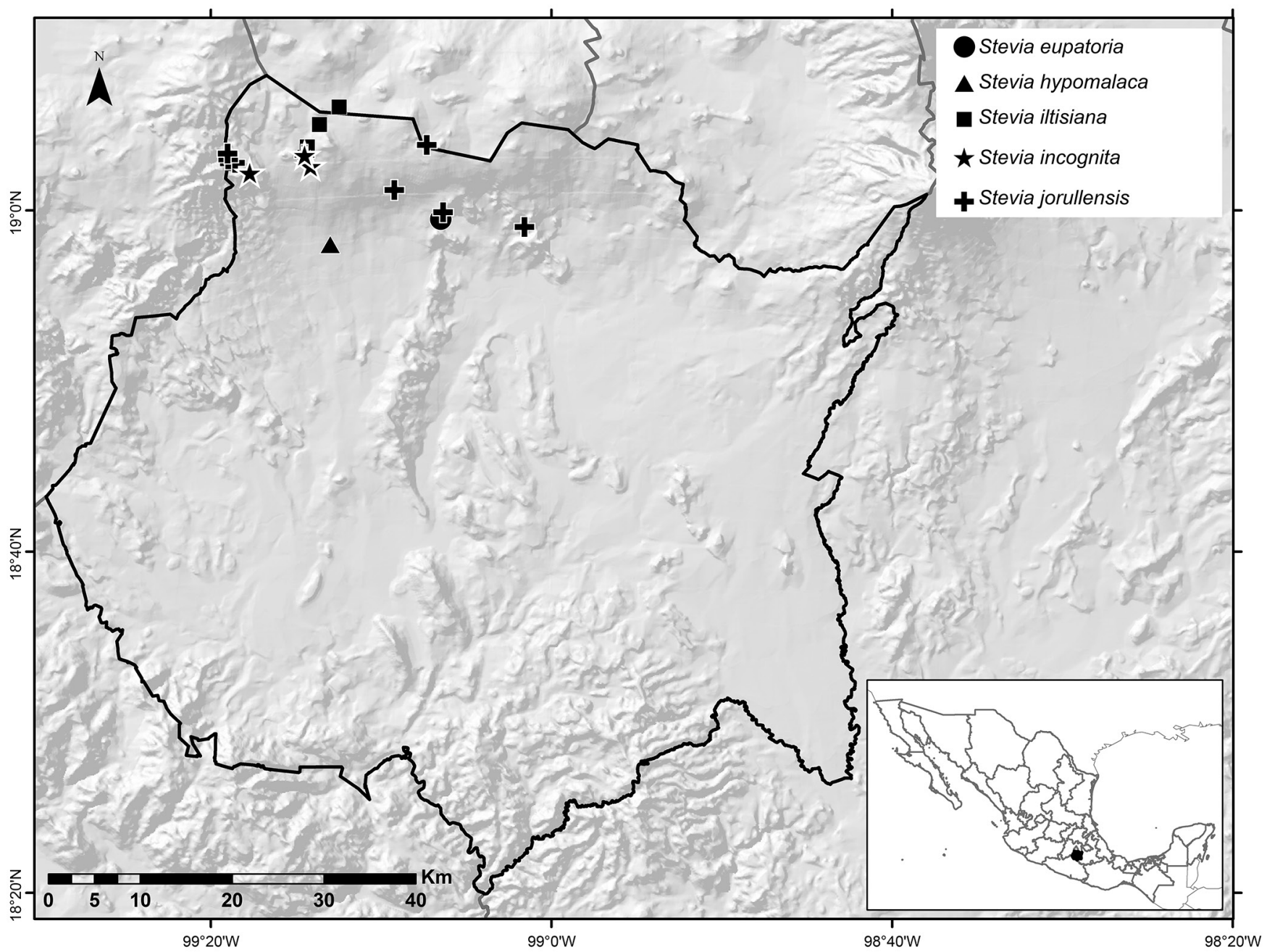

Figura 3: Distribución de Stevia eupatoria (Spreng.) Willd., S. hypomalaca B.L. Rob., S. iltisiana Grashoff, S. incognita Grashoff y S. jorullensis Kunth en el estado de Morelos.

ño o forma, pilosos en superficie abaxial; aquenios 2.2-2.7 $\mathrm{mm}$ de largo, densamente hispidulosos, isomorfos; vilano 3-5 aristas, $4 \mathrm{~mm}$ de largo, escamas libres, 0.5-0.7 mm de largo.

Habitat: bosque de Quercus.

Intervalo altitudinal: $1981 \mathrm{~m}$.

Floración: noviembre.

Distribución en México: Estado de México, Guerrero y Morelos.
Distribución en Morelos: sólo conocida por un par de recolectas, incluyendo a la colección tipo, al noroeste del estado (Fig. 3).

Ejemplares examinados: MÉXICO. Morelos, municipio Cuernavaca, Cuernavaca, C. G. Pringle 1608 (fotografía MEXU).

Stevia hypomalaca se puede llegar a confundir con $S$. serrata Cav., de la cual se diferencia debido a que $S$. serrata tiene la superficie abaxial de las hojas glabrescente a pilosa, y aunque sus venas forman una retícula, ésta no 
está resaltada. En contraste, $S$. hypomalaca tiene la superficie abaxial de las hojas tomentosa y sus venas forman una retícula notablemente resaltada.

8. Stevia iltisiana Grashoff, Brittonia 26: 354. 1974. TIPO: MÉXICO. Ciudad de México, lava fields ca. 2 $\mathrm{km} \mathrm{SSW}$ of La Cima RR station, on either side of old highway 95, on top of Serrania de Ajusco, 3109 m, 14.VIII.1960, H. H. Iltis 948 (holotipo: UC1306958! isotipos: MEXU!, MICH1107747!, TEX00373451!, WIS0257035WIS!).

Hierbas perennes, rizomatosas, con raíces fasciculadas, 0.3-0.6 m de alto; tallo erecto, puberulento a esparcidamente piloso, ramas superiores ascendentes, opuestas; hojas opuestas, en su mayor parte confinadas a la mitad o al tercio inferior de la planta, las superiores sésiles, las inferiores pecioladas, lámina elíptica a ovada, conduplicada, $2.5-4.5 \mathrm{~cm}$ de largo, 1-3 cm de ancho, margen crenado o aserrado, ápice obtuso a redondeado, base obtusa a cuneada y ligeramente decurrente sobre el pecíolo, puberulenta a esparcidamente pilosa, indumento color blanquecino, punteada en ambas superficies con glándulas resinosas, subsésiles, aunque más notables en la abaxial, triplinervada, pecíolo estrechamente alado, 5-15 mm de largo; cabezuelas dispuestas en grupos corimbiformes, compactos y densos, pedúnculos 5-20 mm de largo, puberulentos a pilosos, involucro 5-6 $\mathrm{mm}$ de largo, glabro o glabrescente; corolas 3.5-5 mm de largo, color violáceo-rojizas a moradas, lóbulos iguales o casi iguales en tamaño o forma, pilosos en superficie abaxial; aquenios 2.5$3.7 \mathrm{~mm}$ de largo, esparcidamente hispidulosos, isomorfos; vilano coroniforme, 0.2-0.4 mm de largo.

Hábitat: bosque de Quercus.

Intervalo altitudinal: 2650-3000 m.

Floración: septiembre a enero.

Distribución en México: Ciudad de México, Hidalgo, Morelos, Puebla, San Luis Potosí y Veracruz.
Distribución en Morelos: noroeste del estado (Fig. 3).

Ejemplares examinados: MÉXICO. Morelos, municipio Huitzilac, km 45 de la carretera federal México Cuernavaca, 25.IX.1977, J. Calderón 12 (MEXU); km 59 de la carretera México - Cuernavaca, 2800 m, 23.X.1982, R. Vázquez s.n. (MEXU); Lagunas de Zempoala, 2925 m, 1.VIII.1949, J. G. Teer 49 (MEXU).

Stevia iltisiana es muy similar a $S$. jorullensis, de la que se distingue principalmente porque $S$. jorullensis tiene las hojas distribuidas a lo largo del tallo, por lo general son todas pecioladas y agudas en el ápice. En contraste, S. iltisiana tiene las hojas confinadas a la mitad o al tercio inferior de la planta, las hojas superiores son sésiles y las inferiores pecioladas y son obtusas a redondeadas en el ápice.

9. Stevia incognita Grashoff, Brittonia 26: 357. 1974. TIPO: MÉXICO. Chiapas, Tenejapa, colonia Ach'lum, 2773 m, 10.X.1966, A. S. Ton 1347 (holotipo: MICH1107748!, isotipo: NY00260091!).

Hierbas perennes, rizomatosas, con raíces fasciculadas, 0.4-1.5 m de alto; tallo erecto, puberulento, a menudo con glándulas estipitadas en la parte superior, ramas superiores ascendentes, opuestas; hojas opuestas, distribuidas a lo largo del tallo, pecioladas, lámina ovada, 3-5 $\mathrm{cm}$ de largo, 1.7-3 cm de ancho, margen aserrado a dentado, raras veces crenado, ápice agudo, base por lo general cuneada a obtusa, muy rara vez truncada, ligeramente decurrente, superficie adaxial glabra a pilosa, superficie abaxial puberulenta a esparcidamente hirsuta, en especial a lo largo de las venas, indumento color blanquecino, ambas superficies punteadas con glándulas resinosas, subsésiles, triplinervada, pecíolo alado, 1-3 cm de largo; cabezuelas dispuestas en grupos corimbiformes, compactos y densos, pedúnculos 2-5.5 $\mathrm{mm}$ de largo, con glándulas estipitadas; involucro $6.5-8.5 \mathrm{~mm}$ de largo, con glándulas estipitadas; corolas 5-6.5 mm de largo, color morado, lóbulos iguales o casi iguales en tamaño o forma, pilosos en 
superficie abaxial; aquenios 3.5-4.5 mm de largo, hispidulosos, isomorfos; vilano de escamas libres o coroniforme, $0.5(-1) \mathrm{mm}$ de largo.

Hábitat: bosque de Pinus-Quercus.

Intervalo altitudinal: $1600-3000 \mathrm{~m}$.

Floración: octubre a diciembre.

Distribución en México: Chiapas, Ciudad de México, Coahuila, Estado de México, Guerrero, Hidalgo, Michoacán, Morelos, Nuevo León, Oaxaca, Queretáro y Veracruz.

Distribución en Morelos: noroeste del estado (Fig. 3).

Ejemplares examinados: MÉXICO. Morelos, municipio Huitzilac, Rancho San Lorenzo km 53.5 de la carretera federal México - Acapulco, 2660 m, 7.IX.1989, I. Díaz 1137 (MEXU); $500 \mathrm{~m}$ al SO Lagunas Zempoala y 6 $\mathrm{km}$ al O de Huitzilac, 26.X.1986, G. Flores 351 (MEXU); Tres Marías camino a Zempoala, 2800 m, 8.XI.1995, $T$. Yahara 214 (MEXU), 215 (MEXU), 217 (MEXU).

10. Stevia jorullensis Kunth, Nov. Gen. Sp. 4: 112. 1820. TIPO: MÉXICO. Michoacán, crescit in monti ignivomo Jorullo, $1044 \mathrm{~m}$, octubre (sin año), $A$. J. $A$. Bonpland y F. W. H. A. von Humboldt s.n. (holotipo: P00320134!).

Hierbas perennes, rizomatosas, con raíces fasciculadas, 0.4-1 m de alto; tallo erecto, piloso, ramas superiores ascendentes, opuestas; hojas opuestas, distribuidas a lo largo del tallo, por lo general pecioladas, raras veces sésiles o subsésiles, lámina ovada, algunas veces elíptica, deltada o lanceolada, 1.5-5(-8) cm de largo, 1-3(-5) cm de ancho, margen aserrado o dentado, raras veces crenado, ápice agudo, base cuneada, glabra a pilosa, indumento color blanquecino, punteada con glándulas resinosas en ambas superficies, triplinervada, a veces trinervada en hojas sésiles, pecíolo estrechamente alado, 0-1.5 cm de largo; cabezuelas dispuestas en grupos corimbiformes, compactos y densos, pedúnculos 5-12 mm de largo, puberulentos a pilosos; involucro 5-8 $\mathrm{mm}$ de largo, puberulento; corolas 3-5 mm de largo, color violáceo a moradas, lóbulos iguales o casi iguales en tamaño o forma, pilosos en superficie abaxial; aquenios 3-4 mm de largo, hispidulosos en el ápice, isomorfos; vilano de escamas libres o coroniforme, 0.4-0.8 $\mathrm{mm}$ de largo.

Hábitat: bosque de Abies, Pinus, Pinus-Quercus y Quercus.

Intervalo altitudinal: $2350-3000 \mathrm{~m}$.

Floración: agosto a noviembre.

Distribución en México: Chiapas, Ciudad de México, Coahuila, Durango, Estado de México, Morelos, Guanajuato, Guerrero, Hidalgo, Jalisco, Michoacán, Morelos, Nuevo León, Oaxaca, Puebla, Querétaro, Sinaloa, Tlaxcala, Veracruz y Zacatecas.

Distribución en Morelos: norte y noroeste del estado (Fig. 3).

Ejemplares examinados: MÉXICO. Morelos, municipio Huitzilac, Parque Nacional Lagunas de Zempoala, 2900 m, 24.IX.1986, L. Cardoso 206 (MEXU); autopista México - Cuernavaca km 55, J. Espinosa 252 (MEXU); carretera México - Cuernavaca km 40, 6.X.1989, M. Martínez 52 (MEXU); Dos Ríos, Estación de FCN, F. Salazar s.n. (MEXU); Zempoala, 2800 m, 8.XI.1995, T. Yahara 208 (MEXU). Municipio Tepoztlán, San Juan Tlacotenco, 2920 m, 1.VIII.1987, M. L. Espín 110 (MEXU, TEX); a pie del cerro Tepoztlán, 2350 m, 10.XI.1999, T. Yahara 2032 (MEXU).

11. Stevia micradenia B.L. Rob., Contr. Gray Herb., 64: 3. 1922. TIPO: MÉXICO. Michoacán, dry hills near Pátzcuaro, 24.XI.1891, C. G. Pringle 5051 (holoti- 
po: GH00012747!, isotipos: K000488605!, MEXU!, US00146045!).

Hierbas perennes, rizomatosas, con raíces fasciculadas, $0.3-1.5 \mathrm{~m}$ de alto; tallo erecto, glabro a puberulento, ramas superiores ascendentes, opuestas; hojas opuestas, la mayoría confinadas a la mitad o al tercio inferior de la planta, pecioladas, lámina ovada a lanceolada, $2-5 \mathrm{~cm}$ de largo, 1.5-3.5 cm de ancho, margen crenado o serrado-crenado, ápice obtuso, ocasionalmente agudo, base obtusa, superficie adaxial glabra, márgenes densamente puberulentos, superficie abaxial glabra a puberulenta, indumento color blanquecino, punteada con glándulas resinosas, subsésiles en ambas superficies, triplinervada, pecíolo 1-3 cm de largo; cabezuelas en grupos paniculiformes, amplios y laxos, pedúnculos hasta $20 \mathrm{~mm}$ de largo, con glándulas estipitadas; involucro ca. $5 \mathrm{~mm}$, con glándulas estipitadas; corolas ca. $4.5 \mathrm{~mm}$ de largo, color blanco, lóbulos desiguales en forma y tamaño, pilosos en superficie abaxial; aquenios ca. $2.5 \mathrm{~mm}$ de largo, hispidulosos, isomorfos; vilano coroniforme, 0.3-0.5 mm de largo.

Hábitat: bosque de Pinus-Quercus.

Intervalo altitudinal: $1710-2250 \mathrm{~m}$.

Floración: octubre a diciembre.

Distribución en México: Baja California, Chihuahua, Ciudad de México, Coahuila, Colima, Durango, Estado de México, Guanajuato, Guerrero, Hidalgo, Jalisco, Michoacán, Morelos, Nayarit, Puebla, San Luis Potosí, Sinaloa y Zacatecas.

Distribución en Morelos: norte y noroeste del estado (Fig. 4).

Ejemplares examinados: MÉXICO. Morelos, municipio Tepoztlán, $2 \mathrm{~km}$ al NO de Amatlán, $1710 \mathrm{~m}$, 8.XII.1987, M. L. Espín 490 (MEXU); Tepoztlán, X.1945, F. Miranda 3769 (MEXU).
12. Stevia monardifolia Kunth, Nov. Gen. Sp. 4: 115. 1820. TIPO: MÉXICO. Michoacán, Morelia, 1980 m, octubre (sin año), A. J. A. Bonpland y F. W. H. A. von Humboldt s.n. (holotipo: P00320142!).

Hierbas perennes, rizomatosas, con raíces fasciculadas, $0.4-1.2 \mathrm{~m}$ de alto; tallo erecto, puberulento a tomentuloso, por lo general con glándulas estipitadas en la parte superior, ramas superiores ascendentes, opuestas; hojas opuestas, distribuidas a lo largo del tallo, pecioladas, lámina ovada, rara vez ovado-lanceolada, $3-12 \mathrm{~cm}$ de largo, 2-7 cm de ancho, margen crenado o crenado-serrado, ápice agudo a acuminado, base cuneada a cordada, superficie adaxial glabra a moderadamente puberulenta o hirsuta, superficie abaxial glabrescente a tomentulosa, indumento color blanquecino, ambas superficies punteadas con glándulas resinosas, subsésiles, triplinervada, pecíolo alado, 1.2-4.5 cm de largo; cabezuelas dispuestas en grupos corimbiformes, compactos y densos, pedúnculos 3-8 $\mathrm{mm}$ de largo, pilosos y con glándulas estipitadas; involucro 5.5-8 $\mathrm{mm}$ de largo, con glándulas estipitadas; corolas $5-7 \mathrm{~mm}$ de largo, color violáceo a moradas, lóbulos iguales o casi iguales en tamaño o forma, a veces color blanco, pilosos en superficie abaxial; aquenios 3-4.5 mm de largo, glabros, isomorfos; vilano coroniforme, ca. $0.2 \mathrm{~mm}$ de largo.

Hábitat: bosque de Pinus-Quercus.

Intervalo altitudinal: 2500-3400 m.

Floración: agosto a enero.

Distribución en México: Estado de México, Guanajuato, Guerrero, Hidalgo, Jalisco, Michoacán, Morelos, Oaxaca, Puebla, Querétaro, San Luis Potosí, Tlaxcala y Veracruz.

Distribución en Morelos: principalmente al norte del estado y también al noroeste (Fig. 4).

Ejemplares examinados: MÉXICO. Morelos, municipio Huitzilac, volcán las Palomas, Corredor Biológico 


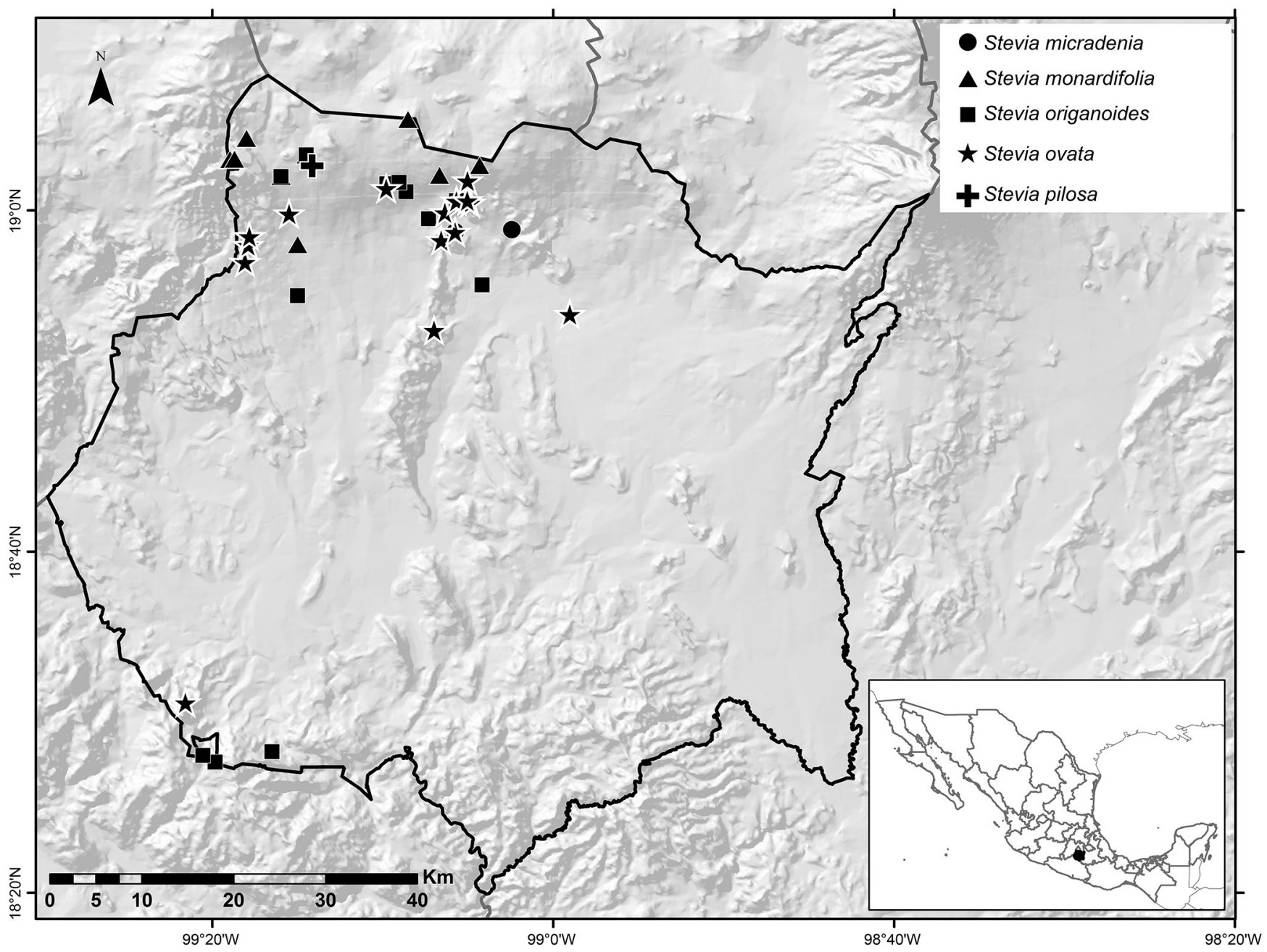

Figura 4: Distribución de Stevia micradenia B.L. Rob., S. monardifolia Kunth, S. origanoides Kunth, S. ovata Willd. y S. pilosa Lag. en el estado de Morelos.

Ajusco - Chichinautzin, $2500 \mathrm{~m}, 22 . \mathrm{XI} .2007$, T. Amezcua 13 (MEXU); ladera S del Lago Acoyotongo, 2850 m, 2.XII.1988, J. R. Bonilla 557 (HUMO); ladera oeste Lago Hueyapan, 2840 m, 3.XII.1988, J. R. Bonilla 576 (HUMO, MEXU); Tres Marías, $50 \mathrm{~km}$ al SO de la Ciudad de México, J. Calderón 72 (MEXU); $53 \mathrm{~km}$ autopista México - Cuernavaca, J. Espinosa 22a (MEXU); $40 \mathrm{~km}$ autopista México - Cuernavaca, E. Matuda 37348 (MEXU); km 12 carr. Huitzilac - Lagunas de Zempoala, 2780 m, 14.IX.1989, R. Ramírez 426 (HUMO); camino de Tres Marías a Zempoala, 2800 m, 8.XI.1995, T. Yahara 200 (MEXU), 220 (MEXU), 221 (MEXU), 222
(MEXU). Municipio Tepoztlán, 2.85 km de la Iglesia de San Juan Tlacotenco, 2800 m, 9.XI.2011, S. Block 1196 (MEXU); $5.5 \mathrm{~km}$ al N de Santo Domingo Ocotitlán, 2870 m, 11.X.1987, M. L. Espín 256 (MEXU, TEX). Municipio Tetela del Volcán, Barrancas, IV.1955, E. Lyonnet 550400011 (MEXU).

13. Stevia origanoides Kunth, Nov. Gen. Sp. 4: 115. 1820. TIPO: MÉXICO. Michoacán, crescit in convalli Sancti Jacobi (Provincia Mechoacanensi), 1530-1800 $\mathrm{m}$, octubre ( $\sin$ año), A. J. A. Bonpland y F. W. H. A. von Humboldt s.n. (holotipo: P00320141!). 
Hierbas perennes, rizomatosas, con raíces fasciculadas, 0.5-1 m de alto; tallo erecto, puberulento a piloso o estrigoso, ramas superiores ascendentes, opuestas; hojas opuestas, a menudo las superiores alternas, distribuidas a lo largo del tallo, subsésiles a pecioladas, lámina lanceolada, lanceolado-oblonga o elíptica, raras veces oblanceolada u ovada, $4-10(-15) \mathrm{cm}$ de largo, 0.6-4 $\mathrm{cm}$ de ancho, margen serrado $\mathrm{u}$ ocasionalmente entero, ápice agudo a obtuso, base atenuada a decurrente, ambas superficies glabras a estrigulosas o estrigosas, indumento color blanquecino, por lo general punteadas con glándulas resinosas, subsésiles, triplinervada, pecíolo alado, 0-2.5 cm de largo; cabezuelas en grupos corimbiformes, compactos y densos, pedúnculos 2-12 $\mathrm{mm}$ de largo, puberulentos a estrigosos; involucro 3.5$4.5 \mathrm{~mm}$ de largo, estriguloso a estrigoso; corolas 3.5-5 $\mathrm{mm}$ de largo, tubo y garganta color blanco a rosado pálidos, lóbulos iguales o casi iguales en tamaño o forma, color blanco, pilosos en superficie abaxial; aquenios ca. $3 \mathrm{~mm}$ de largo, hispidulosos, al menos en el ápice, heteromorfos; vilano de los adelfocarpos, 3 aristas, 4 $\mathrm{mm}$ de largo, escamas 0.3-0.5 mm de largo, el de los idiocarpos de escamas libres o coroniforme, 0.3-0.5 mm de largo.

Hábitat: bosque de Pinus-Quercus y tropical caducifolio.

Intervalo altitudinal: 1800-2900 m.

Floración: octubre a diciembre.

Distribución en México: Aguascalientes, Baja California, Baja California Sur, Chihuahua, Ciudad de México, Colima, Durango, Estado de México, Guanajuato, Guerrero, Hidalgo, Jalisco, Michoacán, Morelos, Nayarit, Oaxaca, Puebla, Querétaro, San Luis Potosí, Sinaloa, Sonora, Tlaxcala, Veracruz y Zacatecas.

Distribución en Morelos: norte y norte noroeste del estado (Fig. 4).
Ejemplares examinados: MÉXICO. Morelos, municipio Cuernavaca, barrancas cerca de Cuernavaca, Pringle 6193 (MEXU). Municipio Huitzilac, $53 \mathrm{~km}$ autopista Cuernavaca, 2370 m, 9.XI.1958, J. Espinosa 107 (MEXU); camino de Tres Marías a Zempoala, $2800 \mathrm{~m}$, 8.XI.1955, T. Yahara 210 (MEXU), 212 (MEXU). Municipio Puente de Ixtla, $1 \mathrm{~km}$ al SE de El Zapote, 1763 m, 24.X.2013, R. Ramírez 3798 (HUMO, MEXU), 3811 (HUMO, MEXU). Municipio Tepoztlán, Pedregal de La Pera, $6.36 \mathrm{~km}$ de la iglesia de San Juan Tlacotenco, 2535 m, 3.XI.2010, S. Block 390 (MEXU), 391 (MEXU); $2.47 \mathrm{~km}$ de la iglesia del pueblo de Tepoztlán, $1850 \mathrm{~m}$, 17.X.2010, S. Block 879 (MEXU); $1.11 \mathrm{~km}$ de la iglesia de San Juan Tlacotenco, 2145 m, 17.XI.2011, S. Block 1244 (MEXU); 3 km NO de Yautepec sobre la carretera federal Tepoztlán, 15.XI.1986, E. F. Cabrera 12238 (MEXU); carretera Cuernavaca - Tepoztlán, F. Miranda 4799 (MEXU); near Parque Station, C. G. Pringle 8703 (LL, MEXU); camino de terracería de Tepoztlán a Coajomulco, 2485 m, 8.XII.2012, G. A. Salazar 8521 (MEXU). Municipio Tlayacapan, cerro El Sombrerito, $1.5 \mathrm{~km}$ de la Capilla del Tránsito, 1700 m, 22.X.1990, R. Cerros 157 (HUMO); barranca Tepecapa, 1920 m, 13.XI.2009, R. Hernández 101 (HUMO).

14. Stevia ovata Willd., Enum. Pl. 2: 855. 1809. TIPO: cultivado a partir de semillas colectadas en México, Lagasca s.n. (posible holotipo: B15204-010!).

Hierbas perennes, rizomatosas, con raíces fasciculadas, 0.4-1.2 m de alto; tallo erecto, crispado-puberulento a piloso, ramas superiores ascendentes, opuestas; hojas opuestas, distribuidas a lo largo del tallo, subsésiles a pecioladas, lámina ovada a rómbica, rara vez ovado-lanceolada o elíptica, $2.5-9 \mathrm{~cm}$ de largo, $1.5-5 \mathrm{~cm}$ de ancho, margen crenado-dentado o serrado, ápice agudo a obtuso, base obtusa a decurrente, ambas superficies esparcidamente puberulentas a pilosas, el indumento color blanquecino, punteadas con glándulas resinosas, subsésiles, triplinervada, las venas sin formar una retícula resaltada, pecíolo alado, 0-2.5 cm de largo; cabezuelas dispuestas en 
grupos corimbiformes, compactos y densos, pedúnculos 5-25 mm de largo, puberulentos a tomentulosos; involucro 3.5-7 $\mathrm{mm}$ de largo, esparcidamente a moderadamente pilósulo; corolas 3-5 mm de largo, tubo y garganta color blanco a rosado pálidos, lóbulos iguales o casi iguales en tamaño o forma, color blanco, pilosos en superficie abaxial; aquenios 3-4 mm de largo, hispidulosos, heteromorfos; vilano de los adelfocarpos, 1-3 aristas, 3.5-5 mm de largo, escamas hasta $0.4 \mathrm{~mm}$ de largo, el de los idiocarpos de escamas libres o coroniforme, 0.2-1 mm de largo, o bien isomorfos, vilano de escamas libres o coroniforme.

Hábitat: bosque de Pinus y Pinus-Quercus.

Intervalo altitudinal: $1200-2650 \mathrm{~m}$.

Floración: agosto a enero.

Distribución en México: Chihuahua, Chiapas, Ciudad de México, Coahuila, Durango, Estado de México, Guanajuato, Guerrero, Hidalgo, Jalisco, Michoacán, Morelos, Nayarit, Querétaro, Oaxaca, Puebla, San Luis Potosí, Sinaloa, Tamaulipas y Veracruz.

Distribución en Morelos: principalmente al norte del estado; también al noroeste y al noreste (Fig. 4).

Ejemplares examinados: MÉXICO. Morelos, municipio Amacuzac, barranquilla que baja a la cascada en la comunidad de El Zoquital, 1305 m, 23.XII.2013, $R$. Ramírez 4331a (HUMO, MEXU). Municipio Tepoztlán, $1.16 \mathrm{~km}$ al oeste de la iglesia de San Juan Tlacotenco, 1735 m, 13.XI.1987, S. Block 402 (MEXU); 1.5 km al este de la iglesia de San Juan Tlacotenco, $2650 \mathrm{~m}$, 22.XI.2010, S. Block 529 (MEXU); $1.55 \mathrm{~km}$ al oeste de la iglesia de San Juan Tlacotenco, 2121 m, 13.XI.2011, S. Block 1309 (MEXU); cerro del Chalchi, $1735 \mathrm{~m}$, 13.XI.1987, M. L. Espín 402 (MEXU, TEX); Tepoztlán, X.1945, F. Miranda 3776 (MEXU). Municipio Yautepec, $5 \mathrm{~km}$ al oeste de Oaxtepec, por la autopista Cuernavaca - Cuautla, 18.XI.1980, J. Calderón 66 (MEXU);
$3.72 \mathrm{~km}$ al este de Yautepec, $1650 \mathrm{~m}, 16$. VIII.1949, J. R. Dixon 69 (MEXU).

Especie con tres variedades, de las cuales sólo la variedad típica (Stevia ovata Willd. var. ovata) se encuentra en Morelos.

15. Stevia pilosa Lag., Gen. Sp. Pl. 26. 1816.TIPO: MÉXICO. Guanajuato, near Guanajuato, s.f., D. L. Neé s.n. (lectotipo: MA245792!).

Hierbas perennes, rizomatosas, con raíces fasciculadas, 0.3-0.7 m de alto; tallo erecto, puberulento a piloso, ramas superiores ascendentes, alternas; hojas alternas, distribuidas a lo largo del tallo, sésiles, lámina linearoblonga a subespatulada, $1.5-4.5 \mathrm{~cm}$ de largo, 0.2-1.4 cm de ancho, margen entero a serrado, ápice obtuso, base atenuada a obtusa, glabra a esparcidamente pilosa, indumento color blanquecino, punteada con glándulas resinosas, subsésiles, en ambas superficies, trinervada; cabezuelas dispuestas en grupos corimbiformes, compactos y densos, pedúnculos pilosos, 2-3 $\mathrm{mm}$ de largo; involucro 5-7 mm de largo, esparcidamente puberulento; corolas 5-7 mm de largo, color violáceo a moradas, lóbulos iguales o casi iguales en tamaño o forma, pilosos en superficie abaxial; aquenios 4-5 $\mathrm{mm}$ de largo, hispidulosos hacia el ápice, isomorfos; vilano de escamas libres, sin aristas, 1-2 mm de largo.

Hábitat: bosque de Pinus-Quercus y tropical caducifolio.

Intervalo altitudinal: $1800-3200 \mathrm{~m}$.

Floración: junio a septiembre.

Distribución en México: Aguascalientes, Ciudad de México, Coahuila, Durango, Estado de México, Guanajuato, Hidalgo, Jalisco, Michoacán, Morelos, Nuevo León, Puebla, Querétaro, San Luis Potosí, Tamaulipas, Tlaxcala, Veracruz y Zacatecas. 
Distribución en Morelos: noroeste del estado (Fig. 4).

Ejemplares examinados: MÉXICO. Morelos, municipio Huitzilac, Rancho San Lorenzo $53.5 \mathrm{~km}$ de la carretera federal México - Acapulco, al SO del poblado de Tres Marías, 2660 m, 7.IX.1989, I. Vilchis 1040 (MEXU); $4 \mathrm{~km} \mathrm{~N}$ of Tres Marías, $47.5 \mathrm{~km}$ from Mexico City, T. Yahara 28 (MEXU). Municipio Tepoztlán, $10 \mathrm{~km}$ al NO de San Juan Tlacotenco, 2980 m, 16.VIII.1987, M. L. Espin 142 (MEXU).

16. Stevia purpusii B.L. Rob., Contr. Gray Herb. 90: 18. 1930. TIPO: MÉXICO. Morelos, arriba de Cuernavaca, 2440 m, 19.XI.1902, C. G. Pringle 11294 (holotipo: GH00012766!, isotipos: ASU0018417!, BRIT24096!, F0051520F!, LL00373461!, MICH1107762!, MO191362!, NY00260125!, RSA0001609!, UC1168154!, US00146075!).

Hierbas perennes, rizomatosas, con raíces fasciculadas, $0.4-0.8 \mathrm{~m}$ de alto; tallo erecto, puberulento a subtomentoso, ramas superiores ascendentes, opuestas; hojas opuestas, distribuidas a lo largo del tallo, pecioladas, lámina ovada a lanceolada, 3-5 cm de largo, 1-3.5 $\mathrm{cm}$ de ancho, margen crenado a serrado, ápice agudo a obtuso, base cuneada a obtusa, puberulentas a tomentulosas en ambas superficies, indumento color blanquecino, punteadas con glándulas resinosas, subsésiles en ambas superficies, triplinervada, pecíolo alado, $0.5-2 \mathrm{~cm}$ de largo; cabezuelas dispuestas en grupos corimbiformes, compactos y densos, ramas opuestas, pedúnculos tomentulosos, 1-2 $\mathrm{mm}$ de largo; involucro 5-7 $\mathrm{mm}$ de largo, con glándulas estipitadas y algunas veces tomentulosas; corolas 4-5 mm de largo, tubo y garganta color violáceo a morados, lóbulos iguales o casi iguales en tamaño o forma, a menudo color blanco, pilosos en superficie abaxial; aquenios 3-3.5 mm de largo, esparcidamente hispidulosos, heteromorfos; vilano de los adelfocarpos, 3 aristas, $3.5 \mathrm{~mm}$ de largo, escamas libres o coroniforme, ca. 0.4 $\mathrm{mm}$ de largo, o bien, isomorfos, vilano de escamas libres o coroniforme, 0.3-0.5 mm de largo.
Hábitat: bosque de Pinus-Quercus y de Quercus, ruderal.

Intervalo altitudinal: 1500-3700 m.

Floración: septiembre a diciembre.

Distribución en México: Aguascalientes, Estado de México, Guanajuato, Guerrero, Hidalgo, Michoacán, Morelos, Oaxaca, Puebla, Querétaro, San Luis Potosí y Veracruz.

Distribución en Morelos: norte y noroeste del estado (Fig. 5).

Ejemplares examinados: MÉXICO. Morelos, municipio Cuernavaca, Parque Morelos, XII.1942, J. R. Bruff 1139 (MEXU); Sierra Morelos, G. B. Hinton 14470 (ENCB, MEXU). Municipio Tepoztlán, Coajomulco, 62 km autopista México - Cuernavaca, 2200 m, 22.XI.1989, M. L. Espín 664 (MEXU); a pie de la montaña Tepoztlán, 2350 m, 10.XI.1999, T. Yahara 2029 (MEXU).

17. Stevia salicifolia Cav., Icon. 4: 32. 1797. TIPO: cultivado en Madrid a partir de semillas provenientes de México, s.f., anónimo s.n. (probable holotipo: MA476383!).

Arbustos, $0.3-2 \mathrm{~m}$ de alto; tallo erecto, puberulento a glabrescente, ramas superiores ascendentes, opuestas o subopuestas; hojas opuestas, distribuidas a lo largo del tallo, sésiles a subsésiles, lámina linear-lanceolada a oblonga o estrechamente elíptica, $1.7-10 \mathrm{~cm}$ de largo, 0.2$1(-1.5) \mathrm{cm}$ de ancho, margen entero a ligeramente serrado, ápice agudo a obtuso, base cuneada, superficie adaxial esparcidamente pilosa en las venas y el margen, superficie abaxial glabra o esparcidamente pilosa en las venas y el margen, indumento color blanquecino, glutinosa, punteada con glándulas resinosas, subsésiles, en ambas superficies, pinnado-nervada a triplinervada; cabezuelas dispuestas en grupos corimbiformes, compactos y densos, pedúnculos puberulentos, 1-5 mm de largo; involucro 4-8 


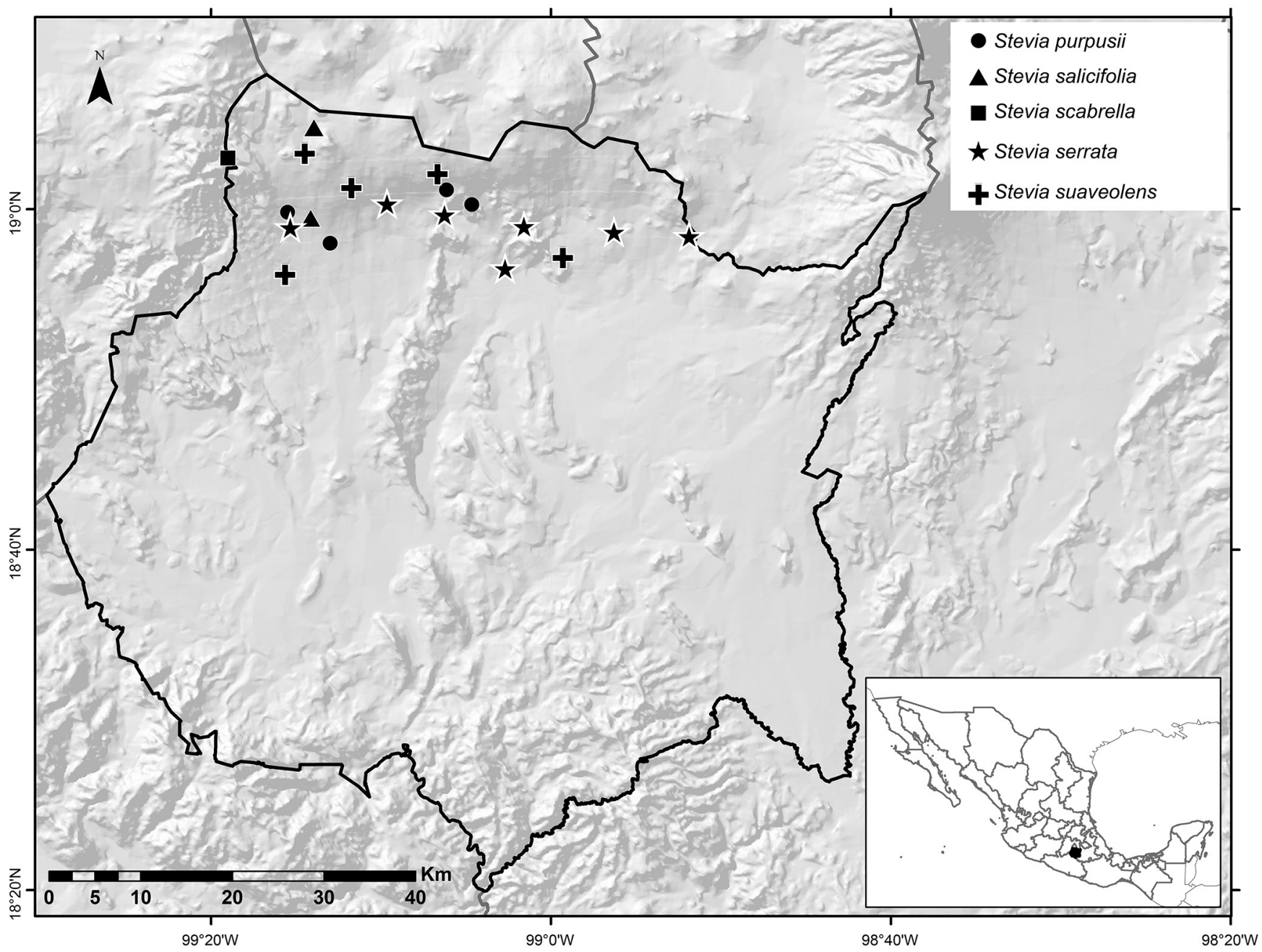

Figura 5: Distribución de Stevia purpusii B.L. Rob., S. salicifolia Cav., S. scabrella Benth., S. serrata Cav. y S. suaveolens Lag. en el estado de Morelos.

$\mathrm{mm}$ de largo, glabro a puberulento, a menudo glutinoso; corolas 4.5-7 mm de largo, color blanco a rosado pálidas, lóbulos iguales o casi iguales en tamaño o forma, glabros en superficie abaxial; aquenios 4-6 mm de largo, hispidulosos, al menos en el ápice, heteromorfos; vilano de los adelfocarpos, 1-3 aristas, 3-5 mm de largo, escamas, 0.2$0.8 \mathrm{~mm}$ de largo, el de los idiocarpos coroniforme, raras veces las escamas libres, $0.2-0.5 \mathrm{~mm}$ de largo, erosas o bien isomorfos, vilano coroniforme, 0.3-0.5 mm de largo.

Hábitat: bosque de Pinus-Quercus, matorral xerófilo, arvense, ruderal.
Intervalo altitudinal: $1500-2700 \mathrm{~m}$.

Floración: junio a noviembre.

Distribución en México: Aguascalientes, Chihuahua, Ciudad de México, Coahuila, Durango, Estado de México, Guanajuato, Hidalgo, Jalisco, Michoacán, Morelos, Nuevo León, Puebla, Querétaro, San Luis Potosí, Sonora, Tamaulipas, Tlaxcala, Veracruz y Zacatecas.

Distribución en Morelos: norte y noroeste del estado (Fig. 5). 
Ejemplares examinados: MÉXICO. Morelos, municipio Cuernavaca, Chamilpa, terreno de la Unidad Biomédica UAEM, 1870 m, 11.XI.1989, J. R. Bonilla 5 (HUMO); N de la UAEM, 6.VI.1977, M. Taboada 72 (MEXU). Municipio Huitzilac, $29 \mathrm{~km}$ al S de la Ciudad de México, a lo largo de la carretera federal a Cuernavaca, 2640 m, 12.X.1965, A. J. Cronquist 10322 (MEXU, TEX).

Se reconocen tres variedades en esta especie; solamente la variedad típica (Stevia salicifolia Cav. var. salicifolia) se encuentra en Morelos.

18. Stevia scabrella Benth., Pl. Hartw. 19. 1839. TIPO: MÉXICO. Jalisco, Bolaños, s.f., K. T. Hartweg 141 (holotipo: K000488705!, isotipos: E00385878!, GH00012773!, LD1225573!, NY002601331!, P00704441!).

Hierbas perennes, rizomatosas, con raíces fasciculadas, o sufrútices, $0.3-1.5 \mathrm{~m}$ de alto; tallo erecto, glabro a puberulento, ramas superiores ascendentes, opuestas; hojas opuestas, distribuidas a lo largo del tallo, pecíolo corto, la base de la hoja decurrente sobre él, lámina ovada a ovado elíptica, $6.5-10 \mathrm{~cm}$ de largo, $2.5-5 \mathrm{~cm}$ de ancho, margen serrado a subentero, ápice agudo a obtuso, base atenuada a obtusa, glabras, aunque punteadas con glándulas resinosas en ambas superficies, triplinervada, venas formando una retícula notablemente resaltada; cabezuelas en grupos corimbiformes, compactos y densos, pedúnculos puberulentos, 5-12 $\mathrm{mm}$ de largo; involucro ca. $6.5 \mathrm{~mm}$ de largo, glabro a puberulento o ligeramente estrigoso; corolas 5-6.5 mm de largo, color blanco a rosado pálidas, lóbulos iguales o casi iguales en tamaño o forma, pilosos en superficie abaxial; aquenios ca. 4.5 $\mathrm{mm}$ de largo, glabros, isomorfos; vilano coroniforme, 0.1-0.3 mm alto.

Hábitat: bosque de Pinus-Quercus.

Intervalo altitudinal: $2800 \mathrm{~m}$.
Floración: agosto a diciembre.

Distribución en México: Chihuahua, Durango, Jalisco, Morelos, Sinaloa y Zacatecas.

Distribución en Morelos: sólo conocida por una recolecta al noroeste del estado (Fig. 5).

Ejemplares examinados: MÉXICO. Morelos, municipio Huitzilac, Zempoala, X.1932, E. Lyonnet 801 (LL, MEXU).

Se reconocen dos variedades en esta especie, de las cuales sólo la variedad típica (Stevia scabrella Benth. var. scabrella) se encuentra en Morelos.

19. Stevia serrata Cav., Icon. 4: 33. 1797. TIPO: cultivado en Madrid a partir de semillas provenientes de México, 1796, anónimo s.n. (holotipo: MA476386!).

Hierbas perennes, rizomatosas, con raíces fasciculadas, $0.3-1 \mathrm{~m}$ de alto; tallo erecto, puberulento a densamente piloso, ramas superiores ascendentes, alternas; hojas alternas o en fascículos alternos dispuestos a lo largo del tallo, sésiles o subsésiles, lámina linear-espatulada, espatulada u oblanceolada, a veces lanceolada o elíptica, a menudo conduplicada, $0.8-6.5 \mathrm{~cm}$ de largo, $0.2-2 \mathrm{~cm}$ de ancho, margen entero a serrado, ápice agudo a redondeado, base cuneada, superficie adaxial glabra a pilosa, glabrescente a pilosa en la superficie abaxial, punteada con glándulas resinosas, subsésiles, en ambas superficies, triplinervada, las venas de la superficie abaxial sin formar una retícula resaltada; cabezuelas dispuestas en grupos corimbiformes, compactos y densos, pedúnculos puberulentos a pilosos, 2-15 $\mathrm{mm}$ de largo; involucro 3.5-6 mm de largo, puberulento a piloso; corolas 3-5 $\mathrm{mm}$ de largo, color blanco, lóbulos iguales o casi iguales en tamaño o forma, pilosos en superficie abaxial; aquenios 2.5-4.5 mm de largo, hispidulosos, al menos en el ápice, por lo general heteromorfos; vilano de los adelfocarpos, 2-5 aristas, 3-5 mm de largo, escamas 0.2-0.5 $\mathrm{mm}$ de largo, el de los 
idiocarpos coroniforme, $0.2-0.6 \mathrm{~mm}$ de largo, o bien, isomorfos, vilano de aristas y escamas.

Hábitat: bosque de Abies, Pinus y Pinus-Quercus, ruderal.

Intervalo altitudinal: $1200-2300 \mathrm{~m}$.

Floración: julio a enero.

Distribución en México: Aguascalientes, Chiapas, Chihuahua, Ciudad de México, Durango, Estado de México, Guanajuato, Hidalgo, Jalisco, Michoacán, Morelos, Nayarit, Nuevo León, Oaxaca, Puebla, Querétaro, San Luis Potosí, Sinaloa, Sonora, Tamaulipas, Tlaxcala, Veracruz y Zacatecas.

Distribución en Morelos: noroeste al noreste del estado (Fig. 5).

Ejemplares examinados: MÉXICO. Morelos, municipio Cuautla, $20 \mathrm{~km}$ al NO de Cuautla, 1950 m, 27.VII.1950, C. E. Boyd 9 (MEXU); $20 \mathrm{~km}$ al NO de Cuautla, 2250 m, 28.VII.1950, C. Humphreys 34 (MEXU). Municipio Cuernavaca, campo turista km 60 carretera México - Cuernavaca, 7.IX.1952, F. Gallegos 454 (MEXU). Municipio Huitzilac, Tres Marías, 1934, G. Gándara 5 (MEXU). Municipio Tepoztlán, autopista México - Tepoztlán, 1860 m, 5.IX.1987, M. L. Espín 170 (MEXU). Municipio Tetela del Volcán, zona S de Tetela del Volcán, E. Estrada 690 (MEXU). Municipio Totolapan, Nepopualco, 16.IX.1977, J. Calderón M-13 (MEXU).

Especie con dos variedades; solamente la variedad típica (Stevia serrata Cav. var. serrata) presente en Morelos.

20. Stevia suaveolens Lag., Gen. Sp. Pl. 27. 1816. TIPO: MÉXICO. Guanajuato, circa Guanajuato, s.f., D. $L$. Neé s.n. (holotipo: MA, no visto).
Hierbas perennes, rizomatosas, con raíces fasciculadas, 0.4-1 m de alto; tallo erecto, densamente puberulento, aracnoideo o tomentuloso, ramas superiores ascendentes, opuestas o alternas; hojas opuestas, a veces las superiores alternas, distribuidas a lo largo del tallo, pecioladas, lámina romboidea a ovado-lanceolada, $2.5-6 \mathrm{~cm}$ de largo, 1.3-3.5 cm de ancho, margen serrado o crenado, ápice agudo, base cuneada a obtusa, superficie adaxial adpreso-puberulenta, superficie abaxial tomentulosa a pilósula, color blanquecino o grisácea, ambas superficies punteadas con glándulas resinosas, subsésiles, triplinervada, pecíolo alado, 0.5-2 cm de largo; cabezuelas dispuestas en grupos corimbiformes, compactos y densos, pedúnculos tomentulosos, 3-8 mm de largo; involucro 5-7.5 $\mathrm{mm}$ de largo, tomentuloso; corolas 4-5 mm de largo, color blanco a pálido-rosadas, lóbulos iguales o casi iguales en tamaño o forma, pilosos en la superficie abaxial; aquenios 3-4 $\mathrm{mm}$ de largo, hispidulosos, heteromorfos; vilano de los adelfocarpos, 1-3 aristas, 4-5 mm de largo, escamas 3-5 $\mathrm{mm}$ de largo, el de los idiocarpos de escamas libres a coroniforme, 0.3-0.7 mm de largo, o bien isomorfos, vilano de escamas libres, erosas, 0.2-0.5 mm.

Hábitat: bosque de Pinus-Quercus y Quercus, arvense.

Intervalo altitudinal: 1380-2900 m.

Floración: octubre a noviembre.

Distribución en México: Chiapas, Durango, Estado de México, Guanajuato, Guerrero, Hidalgo, Michoacán, Morelos, Oaxaca, Puebla, San Luis Potosí, Tlaxcala y Veracruz.

Distribución en Morelos: noroeste al noreste del estado (Fig. 5).

Ejemplares examinados: MÉXICO. Morelos, municipio Cuernavaca, colonia Lomas Atzingo, $1480 \mathrm{~m}$, 18.X.1988, M. Quezada 2002 (HUMO, IEB, MEXU, 
XAL). Municipio Huitzilac, camino de Tres Marías a Zempoala, 2800 m, 8.XI.1995, T. Yahara 209 (MEXU), 211 (MEXU), 213 (MEXU); $7 \mathrm{~km}$ al S de Tres Marías autopista 95 Cuernavaca - Tres Marías, $2620 \mathrm{~m}$, 14.XI.1995, T. Yahara 303 (MEXU). Municipio Tlayacapan, Tlayacapan, 1380 m, 20.X.2011, A. Valiente 10 (MEXU). Municipio Tepoztlán, $2.85 \mathrm{~km}$ al S de la iglesia de San Juan Tlacotenco, 2800 m, 9.XI.2011, S. Block 1212 (MEXU).

21. Stevia subpubescens Lag., Gen. Sp. Pl. 28. 1816. TIPO: MÉXICO. s.f., anónimo s.n. (holotipo: probablemente MA, no visto).

Arbustos, 1-2.5 m de alto; tallo erecto, glabro a puberulento, ramas superiores ascendentes, opuestas; hojas opuestas, distribuidas a lo largo del tallo, cortamente pecioladas, lámina lanceolada a elíptica u oblonga, rara vez ovada, $3.5-11 \mathrm{~cm}$ de largo, $1.5-4 \mathrm{~cm}$ de ancho, margen crenado a entero, ápice agudo a obtuso, base cuneada a decurrente, superficie adaxial glabra o con las venas puberulentas, superficie abaxial esparcidamente puberulenta a tomentulosa a lo largo de las venas, el indumento color blanquecino a grisáceo, ambas superficies punteadas con glándulas resinosas, subsésiles, triplinervada, venas de las hojas sin formar una retícula resaltada, pecíolo 0.5-2 cm de largo; cabezuelas dispuestas en grupos corimbiformes, compactos y densos, pedúnculos 10-15 $\mathrm{mm}$ de largo, puberulentos; involucro 6 $\mathrm{mm}$ de largo, glabro a pilósulo; corolas $4.5 \mathrm{~mm}$ de largo, color blanco, lóbulos iguales o casi iguales en tamaño o forma, pilosos en superficie abaxial; aquenios 4-4.5 mm de largo, hispidulosos, isomorfos; vilano coroniforme, 0.3-1 $\mathrm{mm}$ de largo.

Hábitat: bosque de Pinus-Quercus, Quercus y tropical caducifolio, ruderal.

Intervalo altitudinal: 1960-2900 m.

Floración: octubre a marzo.
Distribución en México: Chiapas, Estado de México, Guerrero, Morelos, Oaxaca, Puebla, Tlaxcala y Veracruz.

Distribución en Morelos: noroeste al noreste del estado (Fig. 6).

Ejemplares examinados: MÉXICO. Morelos, municipio Cuautla, along hwy 115D autopista between Cuautla and Cuernavaca, NW of Cuautla, $3.9 \mathrm{mi}$ SE of jct with hwy 95D between Cuernavaca and Mexico City, T. Croat 65745 (MEXU, MO); Tepetixtla, km 74 carretera México - Cuautla, I. Sánchez 2145 (MEXU). Municipio Cuernavaca, inmediaciones de la Unidad Biomédica, parte E de la UAEM, 2840 m, 18.VI.1989, N. Avonce s.n. (HUMO, MEXU); old hwy 95, km 68, 2 mi N of Cuernavaca City limits, 27.I.1971, J. Freeland 76 (MEXU); Colonia Chamilpa, al N de la UAEM, 1800 m, 8.II.1988, C. Garduño 41 (HUMO); 7 km de Cuernavaca por la carretera Cuernavaca - Toluca, $2300 \mathrm{~m}$, 9.XI.1995, M. Harker 537 (MEXU); Valle de Tepeite, E. Lyonnet 1855 (MEXU); Sierra de Ocuilan, 16.XII.1938, E. Lyonnet 2912 (MEXU); Cuernavaca, 5.III.1940, F. Miranda 222 (MEXU). Municipio Huitzilac, La Pera, Coajomulco, 2230 m, 31.I.1987, M. L. Espín 1 (MEXU); Tres Marías, I.1941, E. Lyonnet 3153 (MEXU); km 56-57 de la carretera México - Cuernavaca, H. Moore 122 (MEXU); near km 59 on toll road between Mexico City and Cuernavaca, D. Porter 1313 (MEXU); 4 km al oriente de Tres Marías, 12.XI.1979, L. Quijano 32 (MEXU); $2 \mathrm{~km}$ al $\mathrm{O}$ de Huitzilac, rumbo a las lagunas de Zempoala, 18.XI.1981, J. L. Villaseñor 146 (MEXU). Municipio Tetela del Volcán, brecha Tetela del Volcán a Tlalmimilulpan, 2100 m, 28.V.1986, J. De la Cruz 1014 (MEXU). Municipio Tepoztlán, 2.97 km al SE de la iglesia de San Juan Tlacotenco, 2755 m, 22.X.2011, S. Block 1018 (MEXU); $6.43 \mathrm{~km}$ al SE de la iglesia de San Juan Tlacotenco, 2560 m, 23.X.2011, S. Block 1037 (MEXU); Santo Domingo Ocotitlán, en el cerro, lado N de la población, 2200 m, 26.IV.1984, M. Gutiérrez 232 (MEXU); Tlacotenco, 2225 m, 2.XII.2003, $T$. 


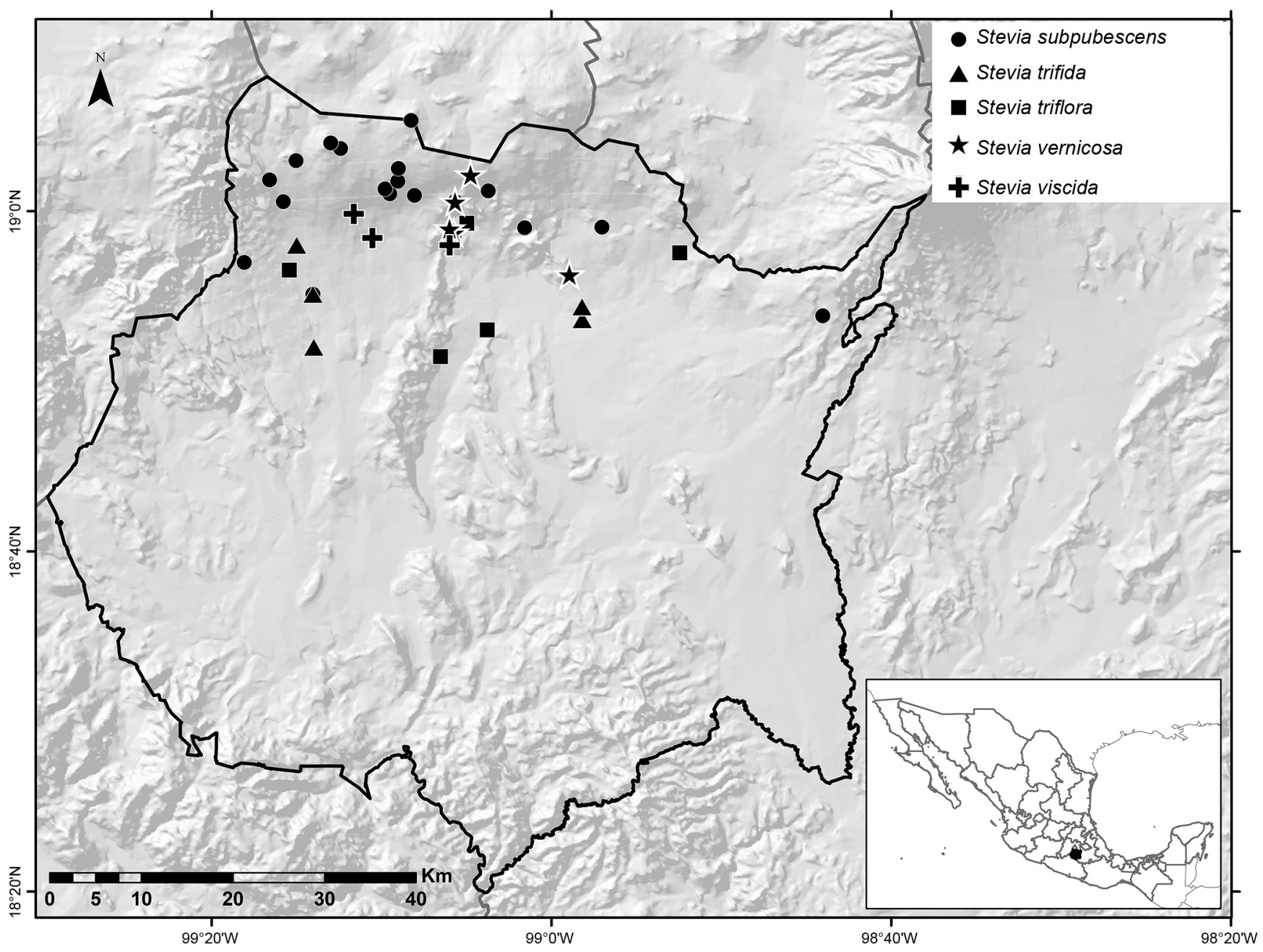

Figura 6: Distribución de Stevia subpubescens Lag., S. trifida Lag., S. triflora DC., S. vernicosa Greenm. y S. viscida Kunth en el estado de Morelos.

Yahara 2900 (MEXU). Municipio Tlayacapan, barranca Tepecapa, 1922 m, 20.XII.2010, R. Hernández 620 (HUMO). Municipio Totolapan, $2 \mathrm{~km}$ al S de Nepopualco, 24.III.1977, J. Calderón 7 (MEXU).

Se reconocen tres variedades en esta especie; solamente la variedad típica (Stevia subpubescens Lag. var. subpubescens) se encuentra en Morelos.

22. Stevia trifida Lag., Gen. Sp. Pl. 27. 1816. TIPO: MÉXICO. s.f., anónimo s.n. (holotipo: probablemente MA, no visto).
Hierbas anuales con raíces primarias, 0.2-0.8 $\mathrm{m}$ de alto; tallo erecto, piloso a puberulento, con glándulas estipitadas, ramas superiores ascendentes, opuestas; hojas opuestas, distribuidas a lo largo del tallo, pecioladas, lámina por lo general 3-lobulada, 2-5 cm de largo, 1.5-4.5 $\mathrm{cm}$ de ancho, lóbulos lineares a oblongos, 0.2-2.1 mm de largo, 0.1-0.3 mm ancho, margen de los lóbulos entero a dentado o lobulado, ápice agudo a obtuso, base acuminada, ambas superficies glabras a pilosas, el indumento color blanquecino, punteadas con glándulas resinosas, subsésiles, y a menudo con glándulas estipitadas, venación pinnada, pecíolo estrechamente alado, 1-3 cm de largo; 
cabezuelas dispuestas en grupos paniculiformes, amplios y laxos, pedúnculos con glándulas estipitadas, $5-12 \mathrm{~mm}$ de largo; involucro 4.5-6 mm de largo, a menudo piloso y con glándulas estipitadas; corolas 3.5-6 mm de largo, garganta y tubo color violáceo-rojizos a morados, lóbulos desiguales en forma y tamaño, color blanco a rosados, pilosos en superficie abaxial; aquenios $2.5-3 \mathrm{~mm}$ de largo, hispidulosos, isomorfos; vilano 3(-5) aristas, $5 \mathrm{~mm}$ de largo, escamas libres o coroniforme, 0.1-0.2 mm de largo.

Hábitat: bosque de Quercus y tropical caducifolio.

Intervalo altitudinal: 1000-2000 m.

Floración: diciembre a mayo.

Distribución en México: Colima, Durango, Estado de México, Guerrero, Jalisco, Michoacán, Morelos, Nayarit, Sinaloa y Sonora.

Distribución en Morelos: noroeste al noreste del estado (Fig. 6).

Ejemplares examinados: MÉXICO. Morelos, municipio Amacuzac, $1.62 \mathrm{~km}$ al SE del puente de la presa Rancho Nuevo, cañada al O del camino a El Zoquital, 963 m, 14.II.2014, R. Ramirez 4541 (HUMO, MEXU). Municipio Cuernavaca, Tetela del Monte, barrancas, IV.1955, E. Lyonnet 550400012 (MEXU); Cuernavaca - Arroyo Seco, E. Lyonnet 541200052 (MEXU); Cuernavaca, 5.III.1940, F. Miranda 230 (MEXU); Cuernavaca, 16.III.1941, F. Miranda 1168 (MEXU); barranca Zampantla, $J$. Vázquez 752 (MEXU). Municipio Puente de Ixtla, El Zapote, 1310 m, 8.II.2004, C. Martínez s.n. (HUMO); Tilzapotla, 2.5 $\mathrm{km}$ al SO, A. Bonfil 447 (MEXU). Municipio Tlaquiltenango, $3.5 \mathrm{~km}$ al SE de Ajuchitlán, 1078 m, 9.XII.1994, R. Cerros 688 (HUMO). Municipio Yautepec, Oaxtepec, ribera del Río Yautepec, 2.V.1952, F. Harking 9 (MEXU); Oaxtepec, 13.III.1952, F. Harking 13 (MEXU); Oaxtepec, 7.XII.1952, F. Harking 599 (MEXU); orilla del Río Oaxtepec, 1600 m, 16.III.1952, F. Matuda 26009 (MEXU).
23. Stevia triflora DC., Prodr. 5: 115. 1836. TIPO: MÉXICO. Oaxaca, San Felipe, s.f., W. F. von Karwinski s.n. (holotipo: G-DC00465224!, isotipos: M0029533!, P00704419!).

Hierbas perennes, rizomatosas, con raíces fasciculadas, $0.4-1.5 \mathrm{~m}$ de alto; tallo erecto, densamente pubescente a tomentuloso, ramas superiores ascendentes, opuestas; hojas opuestas, a veces alternas sólo cerca de la inflorescencia, distribuidas a lo largo del tallo, cortamente pecioladas, lámina ovada, rara vez lanceolado-elíptica, 4-8 cm de largo, $2-5 \mathrm{~cm}$ de ancho, margen crenado-serrado, ápice agudo, base atenuada a decurrente, superficie adaxial puberulenta, punteada con glándulas resinosas, superficie abaxial pilosa a tomentosa, el indumento color amarillento, triplinervada, pecíolo alado, $0.4-2 \mathrm{~cm}$ de largo; cabezuelas dispuestas en grupos corimbiformes, compactos y densos, pedúnculos 2-10 $\mathrm{mm}$ de largo, piloso, color amarillento; involucro 4.5-5 $\mathrm{mm}$ de largo, puberulento; corolas ca. $3 \mathrm{~mm}$ de largo, color blanco, lóbulos iguales o casi iguales en tamaño o forma, pilosos en superficie abaxial; aquenios ca. $2.5 \mathrm{~mm}$ de largo, esparcidamente hispidulosos, isomorfos; vilano coroniforme, 0.2-0.3 $\mathrm{mm}$ de largo.

Hábitat: bosque de Pinus-Quercus, ruderal.

Intervalo altitudinal: 1420-2000 m.

Floración: octubre a diciembre.

Distribución en México: Chiapas, Guerrero, Jalisco, Michoacán, Morelos y Oaxaca.

Distribución en Morelos: noroeste al noreste del estado (Fig. 6).

Ejemplares examinados: MÉXICO. Morelos, municipio Atlatlahucan, $14.48 \mathrm{~km}$ al NO de Cuautla, 1620 m, 14.X.1965, A. J. Cronquist 10335 (ENCB, MEXU). 
Municipio Cuernavaca, Colonia rancho Tetela junto a la barranca El Tecolote, 1420 m, 18.X.1988, M. Quezada 2000 (HUMO, MEXU). Municipio Tepoztlán, Cuitzitlán, cerca de Tepoztlán, 1670 m, 18.X.1987, M. L. Espin 286 (MEXU, TEX); Tepoztlán, X.1945, F. Miranda 3785 (MEXU). Municipio Yautepec, Cañón de Lobos, 26.X.1941, F. Miranda 1612 (MEXU); limestone hills near Yautepec, 1260 m, 29.X.1902, C. G. Pringle 11297 (MEXU).

24. Stevia vernicosa Greenm., Proc. Amer. Acad. Arts 40: 33. 1904. TIPO: MÉXICO. Morelos, on dry ledges, Sierra de Tepoztlán, 2310 m, 15.III.1899, C. G. Pringle 7698 (holotipo: GH00012790!, isotipos: F0051536F!, GOET002087!).

Arbustos, 0.3-0.6 m de alto; tallo erecto, glabro, verrucoso, vernicoso, ramas superiores ascendentes, alternas; hojas opuestas, caducas, salvo las más superiores, pecioladas, lámina lanceolada, elíptica u oblanceolada, 1.5-4 cm de largo 0.3-1.2 cm de ancho, margen aserrado, ápice generalmente obtuso, base atenuada, ambas superficies glabras, punteadas con glándulas resinosas, subsésiles, vernicosas, triplinervada, pecíolo alado, 5-10 mm de largo; cabezuelas dispuestas en grupos corimbiformes, compactos y densos, pedúnculos glabros, verrucosos y vernicosos, 7-35 mm de largo; involucro 6-7 $\mathrm{mm}$ de largo, glabro, vernicoso; corolas ca. $8 \mathrm{~mm}$ de largo, color blanco, lóbulos iguales o casi iguales en tamaño o forma, glabros en superficie abaxial; aquenios 4-5 mm de largo, isomorfos; vilano 4-5 aristas, ca. $8 \mathrm{~mm}$ de largo, escamas, 0.2-0.3 mm de largo.

Hábitat: bosque de Pinus-Quercus.

Intervalo altitudinal: $2200-2340 \mathrm{~m}$.

Floración: febrero a marzo.

Distribución en México: endémica del estado de Morelos.
Distribución en Morelos: principalmente al norte del estado (Fig. 6).

Ejemplares examinados: MÉXICO. Morelos, municipio Tepoztlán, Tepozteco, cerca de la pirámide, 2200 m, 21.III.1987, M. L. Espín 62 (ENCB, MEXU); Tepoztlán, 1700 m, 8.VI.1952, E. Matuda 26347 (MEXU); Tepoztlán, 24.III.1940, F. Miranda 136 (MEXU); Sierra Tepoztlán, 2250 m, 13.II.1907, C. G. Pringle 10349 (ENCB, MEXU); San Juan Tlacontenco, 2320 m, 15.III.1998, T. Yahara 1308 (MEXU).

25. Stevia viscida Kunth, Nov. Gen. Sp. 4: 110. 1820. TIPO: MÉXICO. Michoacán, Morelia, $1800 \mathrm{~m}$, septiembre ( $\sin$ año), A. J. A. Bonpland y F. W. H. A. von Humboldt s.n. 4355 (holotipo: P00320126!).

Hierbas perennes, rizomatosas, con raíces fasciculadas, 0.5-1.5 m de alto; tallo erecto, puberulento a piloso y con glándulas estipitadas, ramas superiores ascendentes, alternas; hojas alternas, formando fascículos distribuidos a lo largo del tallo, sésiles, lámina linear a oblanceolada, conduplicada, $2-8 \mathrm{~cm}$ de largo, $0.3-1(-1.5) \mathrm{cm}$ ancho, margen entero a serrado, ápice obtuso a redondeado, base atenuada, superficie adaxial glabra, punteada con glándulas resinosas, superficie abaxial glabra a pilosa, a menudo pubescente a lo largo de las venas, el indumento color blanquecino, triplinervada; cabezuelas dispuestas en grupos paniculiformes a corimbiformes, amplios y laxos, pedúnculos con glándulas estipitadas, 3-15 mm de largo; involucro 7-10 mm de largo, con abundantes glándulas estipitadas; corolas 6-9 mm de largo, tubo y garganta color violáceo a violáceo-rojizas o moradas, lóbulos desiguales en forma y tamaño, color violáceos pálidos a blancos, pilosos en superficie abaxial; aquenios 5-6 mm de largo, hispidulosos, isomorfos; vilano 3-6 aristas, 6-9 $\mathrm{mm}$ de largo, escamas, 0.2-0.5 mm de largo.

Hábitat: bosque de Pinus-Quercus, arvense.

Intervalo altitudinal: $1000-2500 \mathrm{~m}$. 
Floración: septiembre a noviembre.

Distribución en México: Aguascalientes, Chihuahua, Ciudad de México, Coahuila, Durango, Estado de México, Guanajuato, Guerrero, Hidalgo, Jalisco, Michoacán, Morelos, Nayarit, Nuevo León, Oaxaca, Puebla, Querétaro, San Luis Potosí, Sinaloa, Sonora, Tlaxcala y Zacatecas.

Distribución en Morelos: norte del estado (Fig. 6).

Ejemplares examinados: MÉXICO. Morelos, municipio Cuernavaca, barranca Cilapeña, J. Vázquez 2705 (MEXU). Municipio Tepoztlán, $4 \mathrm{~km}$ al NO de Santa Carina Tlamantlí, 1780 m, 5.IX.1987, M. L. Espín 174 (MEXU); Sierra Chalchi, al S de Tepoztlán, 20.X.1946, F. Miranda 3373 (MEXU).

\section{Discusión}

Bonilla-Barbosa y Villaseñor (2003) reportaron la presencia de 31 especies de Stevia en Morelos. Después de la revisión de ejemplares de herbario recolectados en el estado, se confirma la existencia de solamente 25; la diferencia en el número de taxa radica en la mención por estos autores de nombres que han sido excluidos, al considerarlos malas identificaciones, así como otras especies para las que no se pudo verificar su existencia por no encontrar material de respaldo.

Aunque la superficie del estado de Morelos no es muy extensa ( $4893 \mathrm{~km}^{2}, 0.25 \%$ del territorio total de México), se pudiera pensar que en su territorio se ha llevado a cabo un adecuado esfuerzo de recolecta; sin embargo, este no es el caso. La especie que cuenta con el mayor número de recolectas es Stevia subpubescens (22), seguida de $S$. aschenborniana (17), S. origanoides (16), S. monardifolia (14) y S. trifida (13). Las demás especies contienen menos de 10 registros, cinco de ellas conocidas en el estado solamente por una o dos colectas. Esto puede deberse a que en general los taxa más recolectados se ven favorecidos por el disturbio, por lo que son comunes a las orillas de carreteras, caminos o brechas, lo que facilita su detección y recolección. Además, es necesario un mayor esfuerzo en el inventario florístico, especialmente para complementar el conocimiento sobre la distribución geográfica de las especies a lo largo del estado. Excepto por su porción norte y noroeste, prácticamente el estado carece de registros, como se puede notar en los mapas de distribución (Figs. 2-6). Solamente futuro trabajo de campo permitirá saber si estas zonas realmente carecen de especies del género o han sido pobremente exploradas.

Resulta sorprendente que $S$. vernicosa, un arbusto pequeño con hojas glutinosas (confundido con $S$. lucida o $S$. salicifolia) restrinja su distribución a unas cuantas localidades del municipio de Tepoztlán, lo que la coloca hasta la fecha como una especie endémica del estado. Greenman (1905), en su protólogo citó como un sintipo los especímenes de Purpus 185 (GH, RSA, UC) del Volcán Iztaccíhuatl (Estado de México); sin embargo, Grashoff (1972) lo identifica como S. salicifolia var. salicifolia. Aunque ambas especies tienen suficientes rasgos para considerarlas distintas, es necesario estudiar con más detalle los individuos para clarificar su correcta determinación, lo cual no puede llevarse a cabo eficientemente observando fotografías.

\section{FINANCIAMIENTO}

Parte de este proyecto se realizó con apoyo económico de la Comisión Nacional para el Conocimiento y Uso de la Biodiversidad (CONABIO), durante la conformación de una base de datos para la familia Asteraceae en México. El Consejo Nacional de Ciencia y Tecnología (CONACYT) apoyó con una beca a EVF como Ayudante de Investigador Nacional.

\section{CONTRIBUCIÓN DE AUTORES}

JLV concibió y diseñó el estudio. EVF y OHE revisaron los ejemplares de herbario y realizaron el escrito con la ayuda de JLV. Todos los autores contribuyeron a la discusión, revisión y aprobación del manuscrito final.

\section{AgradeCIMIENTOS}

La asistencia técnica de Enrique Ortiz fue fundamental para la culminación de este trabajo, especialmente en la 
elaboración de las figuras y en el manejo de la información en bases de datos. Se agradece a los curadores de los herbarios citados en la sección de Materiales y Métodos, las facilidades para la consulta de los ejemplares. Guadalupe Segura revisó una versión preliminar del manuscrito y Susana Guzmán-Gómez, encargada del Laboratorio de Microscopía y Fotografía de la Biodiversidad del Instituto de Biología de la Universidad Nacional Autónoma de México (UNAM), ayudó con su experiencia técnica en la elaboración de las imágenes de los aquenios.

\section{LITERATURA CITADA}

Bonilla-Barbosa, J. R. y J. L. Villaseñor. 2003. Catálogo de la Flora del Estado de Morelos. Centro de Investigaciones Biológicas, Universidad Autónoma del Estado de Morelos. Cuernavaca, México. 129 pp.

Bremer, K., A. A. Anderberg, P. O. Karis y J. Lundberg. 1994. Eupatorieae. In: Bremer, K. (ed.). Asteraceae: Cladistics \& Classification. Timber Press. Portland, USA. Pp. 625680.

ESRI. 2010. ArcGIS Desktop 10. Environmental Systems Research Institute. Redlands, USA.

Grashoff, J. L. 1972. A systematic study of the North and Central American species of Stevia. Ph. D. Dissertation. University of Texas. Austin, USA. 609 pp.

Greenman, J. M. 1905. Diagnoses and synonymy of Mexican and Central American spermatophytes. Proceedings of the American Academy of Arts and Sciences 40(1): 2852. DOI: https://doi.org/10.2307/20021952

Hind, D. J. N. y H. Robinson. 2007. XXX. Tribe Eupatorieae. In: Kubitzki, K., J. W. Kadereit y C. Jeffrey (eds.). The families and genera of vascular plants vol. 8. Springer. Berlin, Germany. Pp. 510-574.

King, R. M. y H. Robinson. 1987. Stevia. In: The genera of the Eupatorieae (Asteraceae). Monographs in Systematic Botany. Missouri Botanical Garden. Washington, DC., USA. Pp. 170-175.

Oviedo-Pereira, D., S. Alvarenga V., S. E. Lozano, G. Sepúlveda J. y M. Rodríguez M. 2015. Micropropagación de Stevia rebaudiana Bertoni, un cultivo promisorio para México. BioTecnología 19(2): 14-27.
Robinson, H., E. Schilling y J. L. Panero. 2009. Eupatorieae. In: Funk, V. A., A. Sussana, T. F. Stuessy y R. J. Bayer (eds.). Systematics, evolution and biogeography of Compositae. International Association of Plant Taxonomist. Vienna, Austria. Pp. 731-744.

Turner, B. L. 1997. The comps of Mexico, A systematic account of the family Asteraceae, Vol. 1 Eupatorieae. Phytologia Memories 11: 1-272.

Turner, B. L. 2015. Three new species of Stevia (Asteraceae: Eupatorieae) from Northern Mexico. Phytologia 97(1): 25-31.

Villaseñor, J. L. 2016. Checklist of the native vascular plants of Mexico. Revista Mexicana de Biodiversidad 87(3): 559902. DOI: https://dx.doi.org/10.1016/j.rmb.2016.06.017 
Apéndice 1: Sinonimia y especies excluidas.

Mustelia eupatoria Spreng. = Stevia eupatoria (Spreng.) Willd. Stevia amabilis Lemmon ex A. Gray = Stevia viscida Kunth Stevia angustifolia Kunth = Stevia salicifolia Cav. var. salicifolia Stevia aschenborniana Sch. Bip. var. occidentalis Grashoff = Stevia aschenborniana Sch. Bip.

Stevia benthamiana Hieron. = Stevia ovata Willd. var. ovata

Stevia canescens Kunth = Stevia serrata Cav. var. serrata

Stevia clinopodia DC. = Stevia jorullensis Kunth

Stevia compacta Benth. = Stevia triflora DC.

Stevia conferta DC. = Stevia pilosa Lag.

Stevia conferta DC. var. pilosa (Lag.) DC. = Stevia pilosa Lag.

Stevia conferta DC. var. puberula DC. = Stevia pilosa Lag.

Stevia coronifera DC. $=$ Stevia jorullensis Kunth

Stevia diffusa Greenm. = Stevia aschenborniana Sch. Bip.

Stevia ehrenbergiana Schltdl. = Stevia ovata Willd. var. ovata

Stevia elliptica Hook. \& Arn. = Stevia caracasana DC.

Stevia elongata Kunth var. caracasana (DC.) B.L. Rob. = Stevia caracasana DC.

Stevia fascicularis Less. = Stevia ovata Willd. var. ovata

Stevia flourensioides S.F. Blake = Stevia salicifolia Cav. var. salicifolia

Stevia foliosa Small = Stevia salicifolia Cav. var. salicifolia

Stevia glandulifera Schltdl. = Stevia jorullensis Kunth

Stevia hirsuta DC. $=$ Stevia deltoidea Greene

Stevia hirtiflora Sch. Bip. = Stevia caracasana DC.

Stevia hyssopifolia Cav. = Stevia eupatoria (Spreng.) Willd., no $S$. hyssopifolia Kunth

Stevia hyssopifolia Kunth = Stevia viscida Kunth, no S. hyssopifolia

Cav.

Stevia integra S.F. Blake = Stevia salicifolia Cav. var. salicifolia

Stevia ivifolia Willd. = Stevia serrata Cav. var. serrata

Stevia jorullensis Kunth var. ehrenbergiana (Schltdl.) Sch. Bip. = Stevia ovata Willd. var. ovata

Stevia jorullensis Kunth var. humboldtiana Sch. Bip. = Stevia jorullensis Kunth

Stevia lanceolata Lag. = Stevia serrata Cav. var. serrata

Stevia latifolia Benth. Especie no conocida en el estado de Morelos.

El único ejemplar revisado con este nombre corresponde a una mala identificación por Stevia incognita Grashoff.

Stevia laxa B.L. Rob. \& Seaton = Stevia micradenia B.L. Rob

Stevia laxiflora DC. = Stevia viscida Kunth

Stevia leuconeura DC. = Stevia viscida Kunth

Stevia linoides Sch. Bip. = Stevia serrata Cav. var. serrata

Stevia lozanoi B.L. Rob. = Stevia viscida Kunth

Stevia lucida Lag. var. lucida. Especie no conocida en el estado de Morelos. El único ejemplar revisado con este nombre corresponde a una mala identificación por Stevia vernicosa Greenm.
Stevia microphylla Kunth = Stevia trifida Lag.

Stevia monardifolia Kunth var. macrophylla B.L. Rob. = Stevia monardifolia Kunth

Stevia monardifolia Kunth var. repens B.L. Rob. = Stevia monardifolia Kunth

Stevia multifida DC. = Stevia trifida Lag.

Stevia nepetifolia Kunth = Stevia suaveolens Lag.

Stevia nepetifolia Kunth var. leucantha Sch. Bip. = Stevia suaveolens Lag.

Stevia nervosa DC. = Stevia ovata Willd. var. ovata Stevia origanifolia Walp. = Stevia jorullensis Kunth Stevia pallida Hieron. = Stevia ovata Willd. var. ovata Stevia paniculata Lag. = Stevia ovata Willd. var. ovata Stevia pubescens Lag. = Stevia eupatoria (Spreng.) Willd., no $S$. pubescens Kunth

Stevia pubescens Kunth = Stevia serrata Cav. var. serrata, no $S$. pubescens Lag.

Stevia punctata (Jacq.) Sch. Bip. = Stevia serrata Cav. var. serrata, no S. punctata (Ortega) Pers.

Stevia purpurea Lag. = Stevia viscida Kunth, no $S$. purpurea Pers. Stevia purpurea Pers. = Stevia eupatoria (Spreng.) Willd., no $S$. purpurea Lag.

Stevia purpurea Pers. var. dianthoides Sch. Bip. = Stevia pilosa Lag. Stevia rhombifolia Kunth = Stevia ovata Willd. var. ovata Stevia rhombifolia Kunth var. stephanocoma Sch. Bip. = Stevia triflora DC.

Stevia rhombifolia Kunth var. uniaristata (DC.) Sch. Bip. = Stevia ovata Willd. var. ovata

Stevia salicifolia Cav. var. anathera B.L. Rob. = Stevia salicifolia

Cav. var. salicifolia

Stevia salicifolia Cav. var. integra (S.F. Blake) B.L. Rob. = Stevia salicifolia Cav. var. salicifolia

Stevia scabridula B.L. Rob. = Stevia origanoides Kunth

Stevia seleriana B.L. Rob. Especie sólo conocida del estado de

Oaxaca. Citada erróneamente para Morelos por Bonilla y Villaseñor (2003).

Stevia serrata Cav. var. ivifolia (Willd.) B.L. Rob. = Stevia serrata

Cav. var. serrata

Stevia stenophylla A. Gray = Stevia salicifolia Cav. var. salicifolia Stevia ternifolia Kunth = Stevia ovata Willd. var. ovata Stevia trachelioides DC. $=$ Stevia monardifolia Kunth Stevia uniaristata DC. = Stevia ovata Willd. var. ovata Stevia villosa Moc. ex DC. = Stevia viscida Kunth Stevia viminea Schrad. ex DC. = Stevia connata Lag. Stevia virgata $\mathrm{Kunth}=$ Stevia serrata Cav. var. serrata 
Apéndice 2: Especies que probablemente se encuentran en el estado de Morelos, pero que no se ha verificado su presencia.

Stevia elatior Kunth. Se ha documentado en las delegaciones Tlalpan y Xochimilco de la Ciudad de México, cerca de los límites de Morelos. También hay registros del municipio de Ocuilan, en el estado de México, cerca de sus límites con Morelos.

Stevia micrantha Lag. Se ha documentado en estados vecinos como Ciudad de México, Estado de México y Puebla.

Stevia porphyrea McVaugh. Se ha documentado en el volcán Ajusco, muy cerca de sus límites con Morelos.

Stevia subpubecens Lag. var. intermedia Grashoff. Turner (1997) reporta su presencia en Morelos con base en un ejemplar depositado en MO (Pimentel 2); sin embargo, no fue posible validar su determinación para confirmar la existencia de esta variedad en el estado.
Steva tephra B.L. Rob. Especie frecuente en bosque de Pinus y en vegetación secundaria $(1300-2300 \mathrm{~m})$ de amplia distribución en México. Sin embargo, no se ha observado un ejemplar que respalde su presencia en el estado.

Stevia tomentosa Kunth. Especie de amplia distribución en México. Morfológicamente tiene gran parecido con S. suaveolens, pero el envés de sus hojas es conspicuamente tomentoso. Un ejemplar citado por Grashoff (1972) para Morelos de esta especie (Paray 2535, ENCB) en realidad corresponde a material del estado de México (municipio de Ocuilan). 